\title{
Circulating Endocannabinoids: From Whence Do They Come and Where are They Going?
}

\author{
Cecilia J Hillard ${ }^{*, 1}$ \\ ${ }^{1}$ Department of Pharmacology and Toxicology and Neuroscience Research Center, Medical College of Wisconsin, Milwaukee, \\ WI, USA
}

\begin{abstract}
The goal of this review is to summarize studies in which concentrations of circulating endocannabinoids in humans have been examined in relationship to physiological measurements and pathological status. The roles of endocannabinoids in the regulation of energy intake and storage have been well studied and the data obtained consistently support the hypothesis that endocannabinoid signaling is associated with increased consumption and storage of energy. Physical exercise mobilizes endocannabinoids, which could contribute to refilling of energy stores and also to the analgesic and mood-elevating effects of exercise. Circulating concentrations of 2-arachidonoylglycerol are very significantly circadian and dysregulated when sleep is disrupted. Other conditions under which circulating endocannabinoids are altered include inflammation and pain. A second important role for endocannabinoid signaling is to restore homeostasis following stress. Circulating endocannabinoids are stress-responsive and there is evidence that their concentrations are altered in disorders associated with excessive stress, including post-traumatic stress disorder. Although determination of circulating endocannabinoids can provide important information about the state of endocannabinoid signaling and thus allow for hypotheses to be defined and tested, the large number of physiological factors that contribute to their circulating concentrations makes it difficult to use them in isolation as a biomarker for a specific disorder.
\end{abstract}

Neuropsychopharmacology Reviews (2018) 43, I55-172; doi:10.1038/npp.20 17.130; published online 26 July 2017

\section{INTRODUCTION}

Although the last several centuries have brought fundamental improvements in Western societies that have resulted in significant benefits to human health, these improvements have been accompanied by adverse changes in food intake, sleep patterns, and exposure to psychological stress that contribute to risk for obesity, diabetes, anxiety and depression. Accumulating evidence from preclinical studies demonstrates that the endocannabinoid signaling system is involved in all of these diseases and disorders; hyperactivity of endocannabinoid signaling contributes to excessive intake and storage of high-calorie foods, while endocannabinoid hypoactivity is a risk factor for the development of depression, anxiety and post-traumatic stress disorder. Millennia of human use of cannabis sativa, which contains the endocannabinoid mimetic $\Delta^{9}$-tetrahydrocannabinol (THC), and a brief period in which humans were treated with the endocannabinoid antagonist, rimonabant, provide support for the hypothesis that

${ }^{*}$ Correspondence: Dr CJ Hillard, Medical College of Wisconsin, 8701 Watertown Plank Road, Milwaukee, WI 53226, USA, Tel: +1 414955 8493, Fax: +1 414955 6545, E-mail: chillard@mcw.edu

Received 4 April 2017; revised 29 May 2017; accepted 9 June 2017; accepted article preview online 27 June 2017 endocannabinoid signaling is similarly involved in humans. Thus, better understanding of the endocannabinoid system in humans is an important step toward more sophisticated exploitation of this system to further improve human health.

Assessment of circulating endocannabinoids has been an important but sometimes frustrating approach to the assessment of endocannabinoid signaling in humans. The endocannabinoids are present in the human circulation and their concentrations are dynamic. The purpose of this review is to compile the available data that shed light on several important questions about endocannabinoids that are in the circulation, including: What physiological and pathophysiological factors regulate their concentrations? What are their sources? What are their physiological or pathological roles? Do relative concentrations of circulating endocannabinoids provide clinical information; in other words, are they useful biomarkers?

The available data indicate that circulating endocannabinoids come from multiple organs and tissues, including brain, muscle, adipose tissue and circulating cells. There are hints that endocannabinoids are 'placed' into the circulation to accomplish a specific purpose, as in the regulation of energy intake following exercise. In other cases, it seems more likely that endocannabinoids enter the circulation 


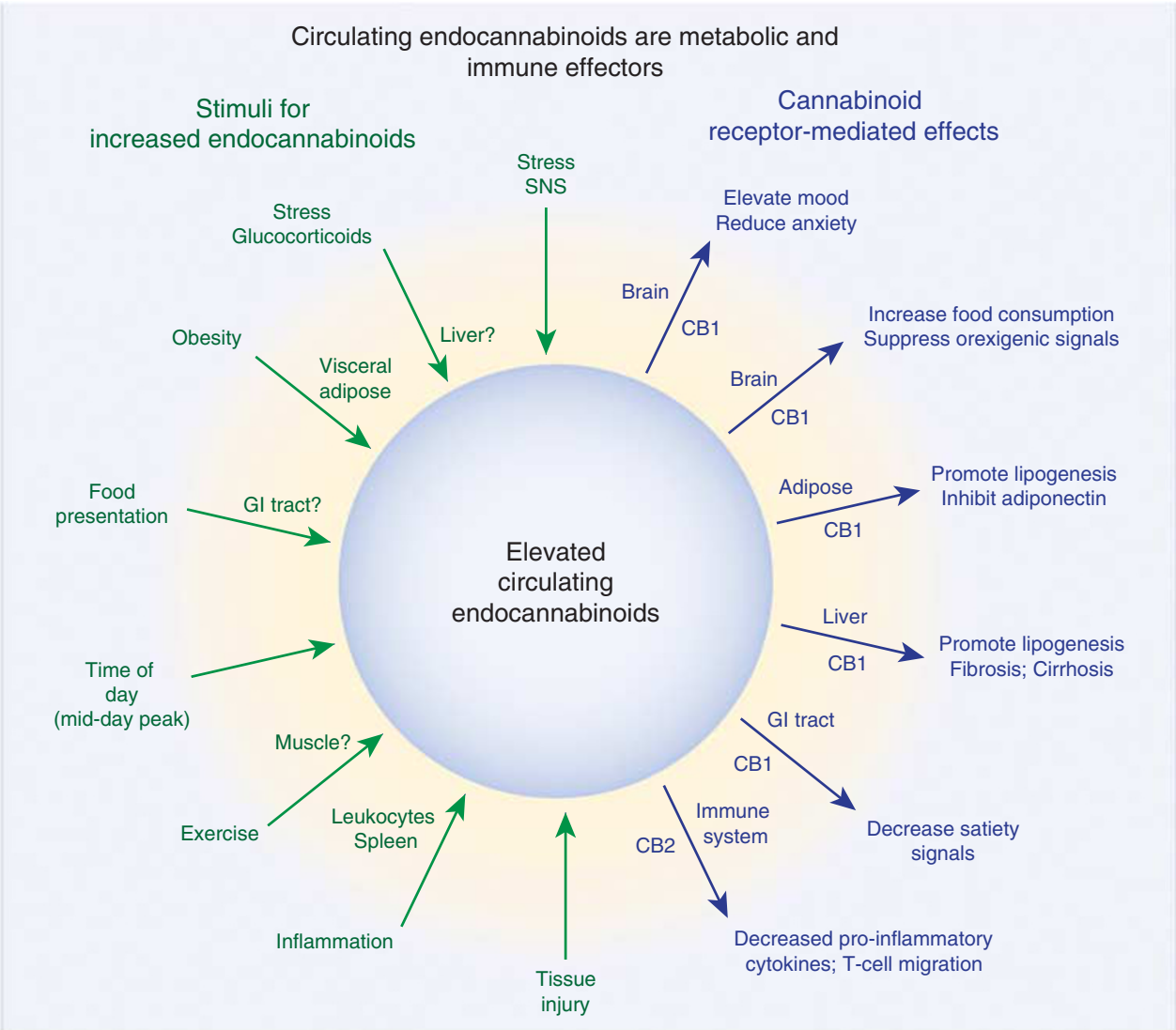

Figure 1. Schematic representing, on the left side, the stimuli and potential sources of endocannabinoids that are present in the circulation and, on the right side, the potential targets of endocannabinoids, together with the cannabinoid receptor subtype that is involved. These concepts are supported by the citations and discussions throughout the review.

by virtue of the fact that they are highly lipophilic and can equilibrate from organs and tissues into the circulation, in other words, are an indirect marker of tissue endocannabinoid tone. The available data also provide some hints and hypotheses regarding the targets of the circulating endocannabinoids, including the metabolic organs and the brain. The key sources and targets supported by data obtained from endocannabinoid measurements in human serum and plasma are shown in Figure 1.

\section{The Endocannabinoids}

The two most well-studied endocannabinoids (defined as endogenous ligands for cannabinoid receptors) are the arachidonic acid derivatives, $\mathrm{N}$-arachidonoylethanolamine (AEA) and 2-arachidonoylglycerol (2-AG). The endocannabinoids are found in all tissues, organs and bodily fluids thus far investigated. Both AEA and 2-AG are endogenous agonists of the canonical cannabinoid receptors, $\mathrm{CB} 1 \mathrm{R}$ and $\mathrm{CB} 2 \mathrm{R}, \mathrm{G}$ protein coupled receptors that have a widespread distribution throughout the body. In addition to the $\mathrm{CB}$ receptors, both endocannabinoids can also bind and activate the vanilloid receptor (TRPV1) and AEA is an agonist for several subtypes of the peroxisome proliferatoractivated receptor (PPAR) family.
The biosynthetic and catabolic pathways for both endocannabinoids have been studied and elucidated to varying degrees (Hillard, 2015). 2-AG is produced as a result of activation of phospholipase C (PLC) in cells that express diacylglycerol lipase. Diacylglycerol lipase converts the PLC product diacylglycerol to 2-acylglycerols, including 2-AG and 2-oleoylglycerol (2-OG). The concentration of 2-OG in human serum is typically $5-10$ times greater than 2-AG. It has been suggested that 2-OG is an endogenous ligand for the orphan receptor GPR119, a receptor that plays an important role in coupling food intake to the release of incretin hormones (Syed et al, 2012).

2-AG is catabolized by hydrolysis of its ester bond, resulting in the formation of glycerol and free arachidonic acid. Several enzymes can accomplish this hydrolysis, including monoacylglycerol lipase (MAGL), alpha-beta hydrolase domain protein (ABHD)-6, and ABHD-12 (Blankman et al, 2007). Because it is metabolized to arachidonic acid by MAGL, 2-AG functions as a precursor for the formation of other arachidonic acid derivatives in the vasculature (Gauthier et al, 2005) and in the brain (Nomura et al, 2008; Viader et al, 2015). In the brain, MAGL activity has been shown to play a role in the regulation of neuroinflammation through this mechanism (Viader et al, 2015). 2-AG can also serve as a substrate for enzymes that metabolize free 
arachidonic acid, including cyclooxygenase 2 (COX2) and some subtypes of lipoxygenase (Urquhart et al, 2015).

AEA and other $N$-acyl ethanolamines (NAEs) are synthesized from a low abundance phospholipid, $N$-acyl-phosphatidylethanolamine (NAPE), through several different pathways (Hillard, 2015). NAPE is synthesized via enzymatically mediated transfer of an acyl chain from the sn-1 position of a donor phosphatidylcholine to the amine of phosphatidylethanolamine (PE). The relative abundance of the NAEs formed reflects the relative abundance of the acyl chains found in the sn-1 position of the donor phospholipids; thus, concentrations of palmitoylethanolamide (PEA) and oleoylethanolamide (OEA) are generally higher than AEA in biological samples, including serum and plasma. PEA and OEA exert anti-inflammatory and anorexigenic effects, respectively likely as a result of interactions with PPAR $\alpha$ (Guzman et al, 2004). The NAEs are catabolized by hydrolysis of the amide bond through the actions of fatty acid amide hydrolase (FAAH) (Cravatt et al, 1996) and $N$-acylethanolamine-hydrolyzing acid amidase (NAAA), which is found primarily in peripheral tissues (Ueda et al, 2001). AEA can also serve as a substrate for COX-2, and lipoxygenase and P450 enzymes that utilize arachidonic acid as a substrate (Urquhart et al, 2015).

\section{Measurement of Endocannabinoids in the Circulation}

Endocannabinoid concentrations in the circulation are typically measured in lipid extracts of serum or plasma obtained from venous blood using isotope-dilution, liquid chromatography-mass spectrometry. Although the endocannabinoids can be measured in both plasma and serum, there is evidence that AEA concentrations are higher in serum than in plasma (Lam et al, 2010) and 2-AG concentrations are more reliably measured in serum (Hillard et al, 2012). Known amounts of deuterated analogs of AEA and 2-AG are added to the serum or plasma samples at the beginning of the extraction process. These analogs are chemically indistinguishable from the naturally occurring molecules, yet have a mass that is 1 dalton higher for every deuterium atom that has been incorporated (usually 8) so can be differentiated from their endogenous counterparts in the mass spectral analyses. As a result, the recovery of the deuterated analog can be measured and provides an excellent estimate of recovery of the endogenous compounds through the extraction and separation procedures.

Blood cells can both release and inactivate AEA (Schmidt et al, 2006; Varga et al, 1998), thus the concentrations of AEA measured in serum or plasma are dependent upon the time between the blood draw and the separation of cells from serum or plasma (Vogeser et al, 2006). As a result, it is best practice to keep the time between blood draw and serum or plasma harvest as consistent as possible to minimize between sample differences in ex vivo generation or loss of AEA. AEA concentrations are stable in serum or plasma after it has been frozen (Jian et al, 2010). The arachidonic acid in 2-AG readily migrates to the 1 position under most storage and extraction conditions (Rouzer et al, 2002). 2-AG and 1-AG migrate at different rates in the standard chromatography used to separate the endocannabinoids. Most methods assume that both 2-AG and 1-AG originate from biological 2-AG and add these peaks together to determine total 2-AG.

Several methods have been published for the extraction of endocannabinoids and related lipids from liquid matrices such as serum and plasma (Gouveia-Figueira and Nording, 2014). A liquid-liquid extraction method has been described in which the sample is mixed with methanol and chloroform with repeated vortexing (De Marchi et al, 2003). Acetonitrile can also be used as the organic solvent and sonication the method of mixing. Solid phase extraction using $\mathrm{C} 18$ columns of the samples that have been made $15 \%$ in ethanol, followed by elution with ethyl acetate is also an effective and reproducible method for endocannabinoid extraction from biological fluids (Hill et al, 2008c). A modification of this approach has been described that utilizes C18-containing pipet tips to reduce the solvent and time needed for extraction (Sergi et al, 2013).

Quantification of the deuterated and endogenous endocannabinoids in each sample is usually accomplished with high-pressure liquid chromatography (HPLC) utilizing a C18 column, followed by mass spectrometry. With the availability of quadrupole, tandem mass spectrometers, species identification and precision of measurement are enhanced because the abundance of daughter ions rather than parent ions are measured. A recent method described the use of on-line sample trapping and microflow liquid chromatography coupled to the use of a tandem mass spectrometer that allowed for detection of the endocannabinoids in $50 \mu \mathrm{l}$ of serum with the use of much less solvent than conventional methods (Kirkwood et al, 2016).

Serum AEA concentrations tend to fall between 1 and $5 \mathrm{nM}$ while serum 2-AG concentrations range from 10-500 nM (see Table 2 in Hillard et al (2012)). Some of the likely reasons for the range in endocannabinoids in healthy individuals are discussed in the sections below, and include time of day and whether the individual has exercised or eaten recently. AEA can bind to the plasma protein, albumin (Giuffrida et al, 2000), although the equilibrium dissociation constant of bovine serum albumin for AEA is $55 \mathrm{nM}$ at $37^{\circ} \mathrm{C}$ (Bojesen and Hansen, 2003), suggesting that the majority of AEA in the circulation is not protein bound. Data regarding the binding of 2-AG to plasma proteins are not available; however, it is likely that its similarity to AEA and arachidonic acid would render it a low affinity ligand for albumin binding sites as well.

Endocannabinoids have been quantified in other biological samples obtained from humans, including saliva (Matias et al, 2012), hair (Krumbholz et al, 2013), semen (Amoako et al, 2010), breast milk (Lam et al, 2010), and amniotic fluid (Lam et al, 2010). Data from endocannabinoid measurements in these biological samples are far less frequent in the literature than measurements in the circulation, however, they could have important advantages. For example, measurement in the hair could provide a retrospective 
picture of endocannabinoids and the saliva is easier to obtain than blood, particularly in a non-hospital setting.

\section{CIRCULATING ENDOCANNABINOIDS AND METABOLIC REGULATION}

The endocannabinoids play a very important role in the regulation of metabolism at systems and cellular levels. As was well stated in a recent review (Mazier et al, 2015): 'The endocannabinoid system exerts regulatory control essentially on every aspect related to search, intake, metabolism and storage of calories...'. Activation of CB1R signaling by the endocannabinoids results in increased consumption of food. In the hypothalamus, tonic endocannabinoid-CB1R signaling functions to maintain food consumption and is suppressed by the homeostatic appetite regulator, leptin (Di Marzo et al, 2001). CB1 receptors are also present in hypothalamic nuclei that modulate energy homeostasis via interactions with ghrelin (Kola et al, 2008). In addition, activation of CB1R signaling enhances reward circuits through effects in the mesolimbic system (De Luca et al, 2012; Mahler et al, 2007; Melis et al, 2007), which potentiates hedonic (reward-driven) consumption of highly palatable foods in particular. Functional imaging of humans performing a reward-driven task following THC find significant attenuation of feedback to the reward circuits compared to placebo administration (van Hell et al, 2012). These studies suggest a particular role for CB1R signaling in feedback inhibition of reward seeking.

$\mathrm{CB} 1 \mathrm{R}$ are also present in peripheral organs involved in energy metabolism, including adipose tissue, the endocrine pancreas, muscle and liver (Bermudez-Silva et al, 2012; Cota et al, 2006; Silvestri and Di Marzo, 2013). Increased CB1R signaling increases energy storage via stimulation of fat mass expansion, glucose uptake and adipogenesis in adipocytes (Vettor and Pagano, 2009); induction of lipogenesis in the liver (Osei-Hyiaman et al, 2005); and increased insulin secretion from the pancreas (Juan-Pico et al, 2006). CB1R signaling also increases processes that reduce energy utilization, including decreased brown fat thermogenesis (Verty et al, 2009) and glucose uptake into skeletal muscle (Liu et al, 2005). Thus, CB1R signaling is coordinated throughout the body to maximize intake and storage of energy. Clearly, this function of the endocannabinoid-CB1R system has great implications for obesity and other components of the metabolic syndrome in humans. In fact, a CB1R antagonist, rimonabant, was found to have significant, beneficial effects in humans to reduce body weight, improve lipid profiles and increase insulin sensitivity before it was removed from clinical use (Van Gaal et al, 2005). In addition, a recent study identified expression of the CB1R in the subfornical organ of the hypothalamus, which is increasing being recognized as a brain region that is responsive to changes in circulating signals of metabolic status (Hindmarch and Ferguson, 2016). This finding suggests that endocannabinoids in the circulation could contribute to the information that is utilized by the brain to alter behavior and physiologic responses.

\section{Circulating Endocannabinoids, Food Consumption and Obesity}

The data discussed above suggest the hypothesis that circulating endocannabinoids coordinate CB1R roles in energy intake and storage among various tissues and organs. In this section, data regarding relationships between circulating endocannabinoids and food consumption, and the correlations among circulating endocannabinoids, body weight and measures of adiposity will be considered. Altogether, these findings support the hypotheses that endocannabinoid concentrations in the circulation are sensitive to several aspects of food consumption and dysregulated in obese and anorexic individuals.

The pattern of change in circulating AEA concentrations surrounding food consumption is consistent with its role as an orexigenic factor in homeostatic (hunger-driven) feeding. Presentation of food (prior to consumption) results in a significant increase in circulating AEA in normal weight (NW) and obese individuals (Gatta-Cherifi et al, 2012) followed by a small but reproducible fall in circulating concentrations of AEA over several hours following food consumption (Gatta-Cherifi et al, 2012; Monteleone et al, 2012, 2015). In NW individuals, the post-meal reduction in circulating AEA is independent of the hedonic value of the meal (Monteleone et al, 2012). Intravenous glucose administration also reduces circulating AEA for several hours following infusion in NW individuals (Di Marzo et al, 2009). Oral consumption of $250 \mathrm{ml}$ of grape juice (41 g sugar) significantly elevated blood glucose levels and reduced circulating 2-AG but did not affect AEA concentrations (Feuerecker et al, 2012a), suggesting that there is a dose dependence to effects of sugars on endocannabinoids in the circulation. The suppressive effects of food and glucose on circulating AEA concentrations could be mediated by increased insulin, since exogenous infusion of insulin also reduces circulating AEA concentrations in the same time frame (Di Marzo et al, 2009). In agreement with this hypothesis, the effect of glucose to reduce circulating AEA was lost in insulin insensitive individuals (Di Marzo et al, 2009); however, another study found that a hyperinsulin/ euglycemic clamp decreased circulating AEA concentrations in both insulin sensitive and insulin resistant obese individuals (Abdulnour et al, 2014). In vitro data demonstrate that normal but not insulin-resistant adipocytes respond to insulin with significant reductions in intracellular concentrations of both AEA and 2-AG (D'Eon et al, 2008).

The response of $2-A G$ to food is affected by its perceived hedonic value, suggesting that $2-\mathrm{AG}$ is involved in rewarddriven (hedonic) feeding. When NW individuals are presented with a favorite compared to a non-favored food, circulating 2-AG concentrations are significantly higher at food presentation, and during and after its consumption (Monteleone et al, 2012, 2015). Sleep deprivation 
promotes increased hedonic eating, particularly in the later part of the day (Benedict et al, 2012; Nedeltcheva et al, 2009; St-Onge et al, 2011) and also increases circulating 2-AG concentrations at mid-day (Hanlon et al, 2016). These findings suggest that circulating 2-AG concentrations reflect activation of reward circuits in the brain and could be a mediator of hedonic eating.

A small study found that neither underweight nor weightrestored individuals with anorexia nervosa exhibited an increase in 2-AG in response to presentation or eating a favorite food (Monteleone et al, 2015). These data are consistent with hypotheses that dysregulated evaluation of rewarding stimuli occurs in anorexia (Keating et al, 2012) and that circulating 2-AG is related to perceived reward. On the other hand, circulating concentrations of AEA declined after favorite and non-favored food consumption in both subgroups of anorexic individuals, patterns that did not differ from NW individuals (Monteleone et al, 2015). These data are consistent with the notion that circulating AEA concentrations are involved in homeostatic and not hedonic feeding processes.

A recent study found that olfactory threshold discrimination identification capacity is significantly lower in obese women than NW and is inversely related to circulating 2-AG concentrations (Pastor et al, 2016). These findings are somewhat counterintuitive since preclinical studies suggest that CB1R signaling in the olfactory epithelium is associated with enhanced sensitivity to oderants (Breunig et al, 2010) and THC exposure can enhance the sensory aspects of food consumption in humans (Brisbois et al, 2011). However, it is possible that the human data reflect downregulation of olfactory $\mathrm{CB} 1$ receptor signaling in response to high 2-AG concentrations.

Regardless of the motivation for overeating or the type of food consumed, excessive food intake over a prolonged period results in obesity. Food-induced changes in circulating endocannabinoids have been characterized in obese individuals to examine the hypothesis that high endocannabinoid tone is associated with obesity. The consumptioninduced reduction in circulating AEA concentrations seen in NW individuals is blunted in insulin insensitive, obese individuals and the magnitude of the decrease in AEA following eating is significantly, inversely correlated with waist circumference (Gatta-Cherifi et al, 2012). Given that these individuals were insulin insensitive in addition to being obese, it is possible that loss of insulin sensitivity underlies both differences in waist circumference and the lack of AEA decrease following food consumption. Interestingly, the premeal increase in AEA is intact in obese individuals, suggesting that the mechanisms underlying the pre-meal increase and post-meal decrease in AEA are different. A second study also found that obese individuals exhibit a loss in the decline in AEA following food consumption, but this change occurs when favorite but not non-favored foods are consumed (Monteleone et al, 2016).

Multiple studies (Abdulnour et al, 2014; Bluher et al, 2006; Cote et al, 2007; Engeli et al, 2005; Fernandez-Aranda et al,
2014; Pastor et al, 2016) (but not all (Di Marzo et al, 2009)) have found that concentrations of 2-AG in blood harvested in the morning after an overnight fast are significantly higher in men and women with body mass index (BMI) values in the obese range compared to NW individuals. Although obese individuals with subcutaneous fat distributions also have elevated 2-AG compared to NW, those with a visceral fat distribution are higher still (Bluher et al, 2006). Furthermore, circulating concentrations of 2-AG are significantly, positively correlated with BMI, total body fat (particularly measures of visceral fat mass) (Bluher et al, 2006) and intra-abdominal adipose (IAA) tissue (Cote et al, 2007). One study also found a significant, positive correlation between BMI and circulating AEA concentrations in individuals with a range of BMI from 18 to 45 (Weis et al, 2010a). Studies that included only or mostly women found that AEA as well as 2-AG are significantly higher in obese than NW individuals (Engeli et al, 2005; Gatta-Cherifi et al, 2012). Conversely, a study in obese men with high amounts of IAA found that AEA concentrations in the morning are significantly lower than normal weight men or obese men with low IAA (Cote et al, 2007). It is possible that differences in the relative distributions of visceral and subcutaneous fat stores between men and women (Enzi et al, 1986) could underlie the sex differences observed in these studies. The one study that did not identify an increase in 2-AG in obese individuals studied a cohort without high visceral fat depots (Di Marzo et al, 2009), which further supports the visceral fat as the source of 2-AG in obesity. In one study (Abdulnour et al, 2014), insulin resistant obese had higher circulating 2-AG concentrations than insulin sensitive; however, the insulin resistant group also had a significantly higher BMI, which could underlie the higher circulating 2-AG. Taken together, these studies suggest that 2-AG enters the circulation from visceral, abdominal fat stores, so its concentration is highest in individuals with the highest amount of visceral fat. Given the roles of 2-AG to increase fat storage in adipose and liver (Mazier et al, 2015) and its ability to promote consumption of highly palatable foods through effects on the brain (Wei et al, 2016), these findings suggest that $2-\mathrm{AG}-\mathrm{CB} 1$ receptor signaling participates in a feed-forward cycle to promote further food consumption and increased body weight gain in the obese. One preclinical study has examined circulating endocannabinoid concentrations in mice made obese through long-term exposure to exogenous glucocorticoids and found that circulating AEA is nearly doubled in the treated, obese mice compared to controls (Bowles et al, 2015). 2-AG concentrations in the circulation were unchanged by the treatment, suggesting that obesity as a result of excess glucocorticoids is mediated by AEA rather than increased 2-AG.

Several studies have examined the expression of FAAH determined in adipose tissue biopsies in relationship to the circulating endocannabinoid concentrations. In postmenopausal women, adipose FAAH expression is reduced in obese women compared to normal weight; and is significantly, negatively correlated with circulating AEA (Engeli et al, 
2005). Interestingly, the same study and another that included both men and women (Bluher et al, 2006) found that adipose FAAH expression is also significantly, negatively correlated with morning 2-AG concentrations. Although $2-A G$ can serve as a substrate for FAAH in vitro (Goparaju et al, 1998), preclinical studies in mice without FAAH expression show no changes in 2-AG content (Patel et al, 2005) which has lead to the widely held assumption that $\mathrm{FAAH}$ does not catabolize 2-AG in vivo. Indeed, the correlation between adipose FAAH expression and circulating AEA is stronger than the correlation with circulating 2-AG (Engeli et al, 2005). It is possible that reduced FAAH expression is a causative factor, resulting in elevated AEA, which, in turn primes the system to increase caloric intake and fat storage through CB1 receptor activation. Adipose fat stores are increased, resulting in an increase in circulating 2-AG, leading to the feed-forward cycle described above. Another study did not find a significant relationship between adipose FAAH activity and BMI or any other measure of metabolic disorder, instead, found that BMI was significantly, positively correlated with adipose MAGL activity in obese without diabetes (Cable et al, 2014). The authors of this study concluded that the rates of catabolism of AEA and 2-AG in adipose do not contribute to their circulating concentrations.

Preclinical findings suggest that a source of circulating endocannabinoids is the small intestine (Dipatrizio et al, 2011). In particular, sham feeding of rats with a lipid meal results in increased endocannabinoid contents in the jejunum via a signal carried by the vagus nerve. Lipid feeding reduced the catabolism of both AEA and 2-AG, resulting in increased tissue contents. Although not studied, it is possible that these lipids enter the portal system and contribute to elevations in circulating concentrations. A recent paper reported that a peripherally restricted CB1R antagonist reduced hyperphagia in mice fed a Western diet (ie, high in carbohydrate and fat), which supports a role for peripheral CB1R signaling in hyperphagia (Argueta and DiPatrizio, 2017).

Although it is not an endocannabinoid per se, preclinical studies suggest the hypothesis that the NAE, OEA, also has important effects on satiety and feeding behavior. In particular, administration of OEA to mice reduces food intake and body weight gain, likely through PPAR-alpha in the GI tract (Fu et al, 2003) and or through actions in the area postrema (Romano et al, 2017). OEA is synthesized by enterocytes of the small intestine in response to fat intake (Fu et al, 2007). In accord with the preclinical findings, hypercholesterolemic patients treated with diets enriched in oleic acid exhibited significantly higher concentrations of plasma OEA concentrations and a significant, negative relationship between plasma OEA and percent body fat (Jones et al, 2014). These data, together with the finding that circulating OEA and AEA concentrations do not change in parallel in response to eating (Monteleone et al, 2016), support the hypothesis that circulating OEA concentrations are regulated by a mechanism that differs from that regulating concentrations of AEA.

\section{Relationships of Endocannabinoid Concentrations with Time of Day and Sleep}

Normalized serum 2-AG concentrations exhibit a significant circadian rhythm in humans under conditions of standardized sleep timing and caloric intake (Hanlon et al, 2015). The average low point (nadir) of 2-AG concentration occurred in this study at 0400 hours, $5 \mathrm{~h}$ after going to bed and $9 \mathrm{~h}$ after the last food consumption. 2-AG concentrations rose steadily from that point, followed by an extended period of maximal concentrations between 1200 and 1500 hours, a time period that encompassed the midday meal at 1400 hours. The return to lower, nocturnal 2-AG concentrations began in the late afternoon/early evening, with a small plateau in 2-AG concentrations occurring between 1700 and 2000 hours, which surrounded the evening meal at 1900 hours. A remarkable threefold change in circulating 2-AG concentration occurred between the nadir and acrophase.

A second study from the same group found that reduction of the number of hours of sleep to four, while maintaining the same sleep period mid-point, produced a significant increase in the amplitude and peak concentrations of 2-AG (Hanlon et al, 2016). In addition, the time of the acrophase was shifted significantly from 1230 to 1430 hours and the mean 2-AG concentrations between 1400 and 2100 hours trended $(p<0.06)$ higher. Thus, restricted sleep increases and extends the peak of $2-A G$ concentrations in the afternoon following sleep restriction. Interestingly, sleep restriction did not affect patterns of 2-AG in the morning and did not affect the nadir concentrations or timing. Instead, the effect of restricted sleep on 2-AG is delayed until later in the day.

In another study, 2-AG concentrations were also found to be elevated in healthy controls exposed to 4 days of restricted sleep, although the timing was different (Cedernaes et al, 2016). In that study, sleep was restricted to $4 \mathrm{~h}$, but the period corresponded to the second half of the normal sleep period (ie, 0245-0700 hours). Under these conditions, 2-AG concentrations in the plasma are significantly elevated at 0830 following restricted sleep compared to normal sleep and are not different at 2030 hours. Midday 2-AG concentrations between normal and restricted sleep phases were not determined in this study. It is possible that the differences in timing of sleep in the restriction paradigm between this study and that by Hanlon (where the sleep midpoint was kept constant) (Hanlon et al, 2016) contributed to the difference in the time at which 2-AG was elevated. If this is the case, it suggests that sleep timing as well as number of hours regulate the chronicity of circulating 2-AG. In this regard, advancing the sleep schedule without changing the light-dark cycle has a moderate effect on the rhythms of melatonin and core body temperature (Danilenko et al, 2003), suggesting that sleep timing can function as a modulator of circadian rhythm. In any case, both studies identified increased circulating 2-AG following restricted sleep.

In a very small pilot study (five subjects) looking at three time points, AEA concentrations in the serum were found to 
be higher upon wakening (0730 hours) than late evening (2230 hours) (Vaughn et al, 2010). Furthermore, one night of complete sleep deprivation results in elevation of serum AEA concentrations later in the day. Both of these results suggest that AEA might have rhythms and relationships to sleep loss similar to those of 2-AG; however, more complete studies need to be carried out to confirm this conclusion.

These data place circulating endocannabinoids, particularly $2-A G$, in the pantheon of molecules which alter metabolism and are circadian. In fact, $2-\mathrm{AG}$ fills a unique role because it is an orexigenic mediator that exhibits its highest concentrations in midday and lowest during sleep. Neither the hormones controlled by the HPA axis nor adipokines and gut hormones reach peak concentrations in the middle of the normal feeding period (Copinschi et al, 2010).

As was pointed out in a commentary (Scheer, 2016) that accompanied (Hanlon et al, 2016), the increases in 2-AG and 2-OG began in the middle of the sleep episode, thus preceding breakfast, awakening and morning light exposure. The timing of food intake, transition from sleep to wakening, and light/dark cycles are all important circadian regulators, but the increases in circulating 2-acylglycerols precede these events, so are not likely driven by them. Glucocorticoids also rise in the morning, and data obtained in rodents indicate that glucocorticoids can rapidly increase 2-AG synthesis in the hypothalamus (Hill et al, 2010). While morning changes in 2-AG paralleled the rise in cortisol, the nadir and acrophase for cortisol were 3-4h earlier than for 2-AG (Hanlon et al, 2015). Thus, 2-AG concentrations appear to have an endogenous, circadian rhythm that differs significantly from those of other metabolic regulators.

Activation of CB1R signaling provides a highly efficacious orexigenic signal (Cota et al, 2006) and the timing of the peak in circulating 2-AG has been hypothesized to engage CB1Rs throughout the body to promote eating during the middle of the active period (Hanlon et al, 2015). In light of the argument presented above that circulating 2-AG is involved in hedonic rather than homeostatic eating, a more specific hypothesis is that midday 2-AG rise promotes food intake for storage, rather than for immediate use. It is interesting in this regard that insulin sensitivity exhibits a robust decrease from morning to evening in healthy human volunteers (Saad et al, 2012; Van Cauter et al, 1997) which is consistent with increased 2-AG-mediated CB1R signaling over that time period. Thus, elevation of 2-AG in situations that could have a significant effect on future metabolic needs, such as chronic loss of sleep, could protect against starvation by promoting an increase in fat stores. This hypothesis is supported by the findings that sleep deprivation both increased feelings of hunger and drive to eat high-calorie foods in the afternoon and increased and shifted the 2-AG acrophase to later times (Hanlon et al, 2016).

The mechanisms that underlie the circadian changes in 2-AG and the shift in pattern that occurs with sleep deprivation are not known. However, given the fact that sleep deprivation is a significant stressor, it is possible that 2-AG concentrations are sustained as a result of stressinduced glucocorticoid elevation.

\section{Circulating Endocannabinoids and Exercise}

The hypothesis that circulating endocannabinoids coordinate a system-wide response to seek, consume and store energy leads logically to the hypothesis that increased energy utilization results in increased circulating endocannabinoids to replenish energy stores. In support of this hypothesis, multiple studies demonstrate that $30-90 \mathrm{~min}$ of moderate exercise increases circulating concentrations of AEA (Heyman et al, 2012b; Raichlen et al, 2012, 2013; Sparling et al, 2003) and other NAEs (Heyman et al, 2012b) immediately after the exercise period, although a recent study did not reveal an immediate increase in AEA (Cedernaes et al, 2016). AEA increases reached significance when heart rate was increased to about $75 \%$ of maximal (Raichlen et al, 2013); neither lower (ie, walking) nor nearmaximal intensities of exercise affected AEA concentrations (Raichlen et al, 2012, 2013) suggesting a 'U-shaped' relationship between exercise and AEA mobilization. Well-trained healthy volunteers who participated in a 'strenuous' hike at altitude below 2100 meters and those who hiked and ascended approximately 2000 meters in altitude both exhibited significant increases in circulating AEA concentrations following the exercise period (Feuerecker et al, 2012b). Interestingly, hypoxic stress of exercise at high altitude appeared to potentiate the increase in AEA in this study. A preclinical study utilizing hepatic ischemia-reperfusion injury also found that $2-\mathrm{AG}$ is increased in response to ischemia, which could reflect regulation of endocannabinoids by the state of oxygenation of tissues (Kurabayashi et al, 2005).

A few studies have examined chronic effects of physical exercise on baseline endocannabinoids. A study of NW and obese women found that moderate-vigorous physical activity measured over 6 days is positively correlated with circulating AEA concentrations (Fernandez-Aranda et al, 2014). Interestingly, high circulating AEA concentrations are also associated with high BMI. On the other hand, no differences in basal concentrations of AEA and 2-AG were found between active and sedentary NW men in another study (Gasperi et al, 2014).

The effects of exercise on circulating 2-AG concentrations have been less consistent. Studies that employed 30-90 min of sustained exercise and observed increases in AEA did not find an increase in 2-AG (Heyman et al, 2012b; Raichlen et al, 2012, 2013; Sparling et al, 2003). However, another study employing an exercise regimen known to induce exercise-induced hypoalgesia ( $3 \mathrm{~min}$ of isometric contractions of the forearm) found that 2-AG is increased very significantly, in addition to the NAEs (Koltyn et al, 2014). Another study found an increase in 2-AG measured in blood collected $15 \mathrm{~min}$ after a $30 \mathrm{~min}$ exercise period (Cedernaes 
et al, 2016); however, the subjects in this study were not given food in the morning of the experiment, which could have resulted in a more physiologically stressful paradigm than exercise alone. Thus, the available data are most consistent with a hypothesis in which moderate levels of sustained (ie, more than $30 \mathrm{~min}$ ) exercise increase AEA and other NAEs in the circulation while 2-AG increases in response to short bursts of activity, perhaps specifically in response to isometric contractions.

It is possible that the increased endocannabinoids in the circulation following exercise come from skeletal muscle. Messenger RNAs encoding NAPE-specific phospholipase D (Hutchins-Wiese et al, 2012), and diacylglycerol lipase (Crespillo et al, 2011) are present in skeletal muscle. PEA and another NAE, stearoylethanolamide, are increased by exercise in microdialysates of the trapezius muscle in individuals with chronic neck/shoulder pain (Ghafouri et al, 2013), providing additional support for the hypothesis that endocannabinoids can be produced in muscle. It is well established that exercise increases circulating glucocorticoid concentrations (Urhausen et al, 1995); and exogenous glucocorticoid treatment produces a rapid increase in brain AEA concentrations (Hill et al, 2010), suggesting a possible link between glucocorticoid receptor activation and AEA synthesis.

Endocannabinoid mobilization during exercise is very consistent with the role of CB1R signaling in the regulation of metabolism discussed above. Activation of CB1R in the liver and adipose move the system toward energy storage and thus can serve to both restrain energy use and contribute to recovery of energy stores following exercise (Pagotto et al, 2006). DiMarzo and colleagues have suggested an interesting hypothesis that AEA and other NAEs could produce positive metabolic effects locally in skeletal muscle, including enhanced glucose uptake, improved insulin action, and mitochondrial biogenesis via activation of $\operatorname{PPAR} \gamma$ (Heyman et al, 2012a). Although endocannabinoids can also act centrally to increase food consumption, a recent study found that exercise-induced increases in endocannabinoids were not correlated with feelings of subjective hunger (Cedernaes et al, 2016), suggesting that any metabolic role for the circulating endocannabinoids is likely to be more peripheral than central. A study in healthy cyclists demonstrated a significant, positive correlation between the increase in circulating AEA and an increase in the neurotrophic factor, BDNF, following a $90 \mathrm{~min}$ exercise period (Heyman et al, 2012b). Although the directionality of this relationship is not known, acute administration THC to healthy, non-cannabisusing humans also increases serum BDNF concentrations (D'Souza et al, 2009), suggesting that BDNF synthesis/ release is evoked by CB1R activation. Preclinical studies in the CNS are also consistent with CB1R regulation of BDNF (Khaspekov et al, 2004; Marsicano et al, 2003). These data suggest that endocannabinoids could be the mediators of exercise-induced increases in BDNF (Szuhany et al, 2015) and, thus, of the hypothesized effects of exercise on cognitive function and mood (Phillips et al, 2014).

\section{CIRCULATING ENDOCANNABINOIDS AND INFLAMMATION}

Circulating endocannabinoids are significantly increased in several conditions in which there is systemic inflammation. For example, both 2-AG and AEA are folds-higher in the serum of patients with endotoxic shock than control serum (Wang et al, 2001). Circulating endocannabinoids are increased in patients with cirrhosis (Fernandez-Rodriguez et al, 2004); chronic hepatitis C infection (Patsenker et al, 2015); exposure to solar ultraviolet radiation (Felton et al, 2017); congestive heart failure (Weis et al, 2010b); and atherosclerosis (Maeda et al, 2009). Similarly, rats with acute pancreatitis also exhibit significantly elevated circulating AEA concentrations, particularly in animals with a severe, necrotizing pancreatitis (Matsuda et al, 2005). When activated, macrophages (Di Marzo et al, 1999; Varga et al, 1998), platelets (Varga et al, 1998), T and B cells (Sido et al, 2016) release endocannabinoids ex vivo, and so could be a source of circulating endocannabinoids. On the other hand, a recent study carried out in patients undergoing hematopoietic stem cell transplantation (HCT) suggests that bone marrow-derived immune cells per se may not be an important source of 2-AG (Knight et al, 2015). In particular, no change in 2-AG concentrations occurred between the period in which the HCT patient's immune system is ablated and after immune system reconstitution. Preclinical studies suggest two alternative hypotheses. First, it is possible that non-immune cells respond to inflammatory mediators with increased endocannabinoid release as has been shown in inflamed hepatocytes (Batkai et al, 2007). Second, inflammation results in a reduction in 2-AG catabolism by splenic carboxylesterase $2 \mathrm{~g}$ in the spleen (Szafran et al, 2015), suggesting that the rise in 2-AG during inflammation could be the result of spillover from the spleen, which is enhanced as a result of decreased 2-AG hydrolysis in that tissue.

2-AG is an agonist of the CB2 receptor (Soethoudt et al, 2017), a GPCR that is expressed constitutively by human B and $\mathrm{T}$ cells; macrophages and, to a lesser extent, neutrophils (Galiegue et al, 1995). CB2R activation is associated with a reduction in proinflammatory cytokine release (Leleu-Chavain et al, 2013; Patsenker et al, 2015) and with reduced migration of $\mathrm{T}$ cells into the brain (Maresz et al, 2007). The findings that 2-AG can be elevated during inflammation and that it activates an anti-inflammatory receptor suggest the hypothesis that endocannabinoids function as a feedback system to dampen inflammation. A recent preclinical study highlights this relationship. In this study, antigen activation of macrophages and dendritic cells resulted in increased 2-AG and CB2R antagonist treatment increased antigen-specific immune responses in mice, suggesting that 2-AG/CB2R activation suppresses innate and adaptive immune responses in mice (Dotsey et al, 2017).

In contrast to these hypotheses, several studies have found significant, positive correlations between circulating 2-AG concentrations and concentrations of the pro-inflammatory cytokine interleukin-6 (IL-6) (Knight et al, 2015; Weis et al, 
2010a), data that do not reconcile with this hypothesis. If 2AG is anti-inflammatory even to a small extent, one would expect a negative relationship between IL-6 and 2-AG. In this regard, 2-AG potentiates LPS-stimulated IL- 6 expression in a macrophage cell line (Marazzi et al, 2011). On the other hand, plasma concentrations of $2-A G$ and the cytokine, tissue necrosis factor alpha, were found to be significantly negatively correlated in another study (Koppel et al, 2009).

The relationships between $2-A G$ and cytokines in the circulation need further study as does the fundamental question of whether circulating endocannabinoids participate in regulation of inflammation in humans. In this regard, several of the conditions described above in which circulating endocannabinoids are elevated also result in inflammation, including acute bouts of exercise (Ruderman et al, 2006) and obesity (Marsland et al, 2010), data that support the possibility that there are connections between endocannabinoids and inflammation. Activation of CB1R signaling in the context of inflammation can be a contributing factor to fibrosis and other detrimental effects of chronic inflammation (Iyer et al, 2017). Circulating concentrations of AEA are elevated in patients with cirrhosis and their concentrations are positively correlated with negative indices of liver function (Caraceni et al, 2010).

\section{CIRCULATING ENDOCANNABINOIDS AND STRESS}

Exposure to physical and psychological stressors result in coordinated behavioral, endocrine and neuronal changes that increase chances for survival if an injury does happen. Acute stress responses include activation of the sympathetic nervous system and the hypothalamic-pituitary-adrenal (HPA) axis. Stress exposure also produces consistent and reproducible increases in inflammation systemically and in the brain, likely as a downstream consequence of sympathetic activation (Dantzer et al, 2008). For example, acute psychological stress results in an immediate increase in natural killer $\mathrm{T}$ cells and interleukin 1beta (IL-1 $\beta$ ) (Yamakawa et $a l, 2009$ ) and a delayed (90 min) increase in IL-6 (Steptoe et al, 2007). Sympathetic activation results in migration of monocytes and macrophages into the circulation and triggers release of IL- $1 ß$ and other cytokines (Yamakawa et al, 2009).

Preclinical data support the hypotheses that endocannabinoid signaling is altered by stress and mediates or modulates stress responses (Hillard, 2014). Evidence obtained in brain demonstrate that 2-AG mobilization can occur downstream of glucocorticoid receptor activation (Di et al, 2005) while AEA is elevated by corticotropin releasing hormone receptor activation, secondary to inhibition of FAAH (Gray et al, 2015). Endocannabinoid/CB1R signaling inhibits the activation of the HPA axis by stress (Hill et al, 2009a) and enhances recovery following stress offset (Hill et al, 2011).

CB1R are present on sympathetic nerve terminals and their activation results in sympathomimetic effects in preclinical studies (Ishac et al, 1996; Pfitzer et al, 2005). However, AEA infused intra-arterially in the human forearm failed to affect blood flow (Movahed et al, 2005), suggesting that CB1R activation may not affect release from sympathetic nerve terminals in healthy humans. Preclinical studies demonstrate that $\mathrm{CB} 1 \mathrm{R}$ signaling in the nucleus tractus solitarius (NTS) potentiates the sympathoinhibitory responses to activation of the baroreceptor reflex (Chen et al, 2010; Seagard et al, 2004, 2005). On the other hand, $\mathrm{CB} 1 \mathrm{R}$ activation in the periaqueductal gray (PAG) increases activity of the SNS (Dean, 2011).

\section{Effects of Acute Stress on Circulating Endocannabinoids}

Activation of the SNS as a result of inducing postural hypotension with a head up tilt is accompanied by a significant increase in 2-AG concentrations (Schroeder et al, 2009). However, associations between 2-AG concentrations and measures of sympathetic activation were not found (Schroeder et al, 2009). In the same study, circulating concentrations of AEA were significantly, positively correlated with the ability of patients to tolerate the procedure without fainting (Schroeder et al, 2009). This result suggests a positive relationship between AEA and SNS activity.

Vestibular activation of the SNS triggers nausea and vomiting (Balaban, 1999); and parabolic flight maneuvers that trigger motion sickness produce an immediate increase in circulating AEA concentrations and a delayed (recovery phase) increase in 2-AG (Chouker et al, 2010). Increases in both 2-AG and AEA concentrations are associated with less motion sickness, which is consistent with preclinical and human data that exogenous activation of CB1R signaling reduces nausea and vomiting (Sticht et al, 2015).

Hyperemesis is a significant physiological stress and is accompanied by increases in both SNS and HPA axis activation. Cyclic vomiting syndrome (CVS) is a functional disorder characterized by relapsing and remitting bouts of prolonged nausea and vomiting. Since endocannabinoids are elevated during stress and can reduce nausea and vomiting, circulating endocannabinoids were compared between sick (active vomiting) and well phases in individuals with CVS (Venkatesan et al, 2016). Concentrations of both AEA and 2-AG are elevated in the sick compared to well phases, but the increases did not reach statistical significance $(p=0.09$ for both). Concentrations of both PEA and OEA were significantly increased and positively correlated with the amount of distress. No significant associations between circulating endocannabinoid concentrations and circulating cortisol or salivary amylase measured at the same time were found in this study.

Acute exposure to psychological stress also elevates circulating endocannabinoid concentrations. A commonly used procedure to evoke psychological stress in humans in a laboratory setting is the Trier Social Stress Test (TSST). There are various forms of the TSST, but most include 
public speaking and solving difficult arithmetic problems (Allen et al, 2014). The TSST results in activation of both the SNS and HPA axis as well as an increase in perceived anxiety. Administration of a seventeen-minute version of the TSST resulted in a significant increase in 2-AG concentrations immediately afterwards that returned to basal concentrations $30 \mathrm{~min}$ after the end of the stress (Hill et al, 2009b). Serum AEA concentrations were not significantly different from baseline at either time point. However, a second study found that a shorter stress period $(5 \mathrm{~min})$ produced no significant change in 2-AG concentrations, but significantly increased circulating AEA concentrations immediately after the stress (Dlugos et al, 2012). Interestingly, this study also found preliminary evidence of differences in the endocannabinoid response among males and females in each phase of their menstrual cycles, with males exhibiting a greater increase from baseline than females, particularly females in the follicular phase. This study also found preliminary evidence of differences in the endocannabinoid response to stress between those of African and Caucasian descent. The change in PEA from baseline to after stress was significantly, positively correlated with the change in cortisol measured in the same samples; the change in AEA concentration was not significantly associated with cortisol.

A study in which imagery of a previous stressful experience was administered found that AEA concentrations were not changed from baseline but were significantly lower than baseline $75 \mathrm{~min}$ after the end of the stress (Mangieri et al, 2009), which is reminiscent of the effects of food consumption on circulating AEA concentrations discussed above.

Thus, while these studies all demonstrate that circulating endocannabinoid concentrations are sensitive to acute, psychological stress, they also indicate that the relationships are complex, time-dependent, and affected by sex. Circulating concentrations of both AEA and 2-AG can be affected by acute stress, but studies of associations with the primary stress effector systems, the HPA axis and SNS, do not consistently find evidence of a direct relationship between activation of these systems and concentrations of endocannabinoids in the circulation. However, preclinical studies indicate that the function of elevated endocannabinoids during stress is to buffer the stress response and hasten return to homeostasis through inhibition of the HPA stress response in particular. Thus, if endocannabinoids in the circulation are both downstream and upstream of the HPA axis, the relationships between endocannabinoid and cortisol concentrations would likely be nonlinear and dependent upon timing and individual responsivity of both systems. It is also possible that changes in endocannabinoid concentrations occur with a time delay, so that concentrations of cortisol or measures of SNS are not related when examined at the same point in time. Models that allow for these complexities to be assessed are needed to answer this question.

\section{Circulating Endocannabinoids and Chronic SNS or HPA Axis Activation}

Although there is little evidence that circulating endocannabinoids are associated with any measure of SNS activation at baseline, several studies suggest that AEA is associated with SNS-mediated physiological effects in various pathological conditions. For example, AEA concentrations are higher in individuals with sleep apnea and are strongly, positively correlated with both systolic and diastolic blood pressure, independent of BMI and insulin resistance (Engeli et al, 2012). Interestingly, depressed women also exhibit a significant, positive correlation of circulating AEA concentrations and diastolic blood pressure, with a trend $(p<0.07)$ toward a significant association with systolic pressure as well (Ho et al, 2012). Intravenous injections of AEA in experimental animals reduce blood pressure (Ho and Gardiner, 2009), suggesting that the relationship underlying the correlation between circulating AEA concentrations and blood pressure is that elevated blood pressure results in increased AEA. Indeed, increased blood pressure in rats produces an elevation of AEA concentrations in the NTS (Seagard et al, 2004). On the other hand, circulating concentrations of AEA are significantly reduced in individuals with preeclampsia, a condition associated with hypertension in late pregnancy (Molvarec et al, 2015), suggesting that increased blood pressure alone is not sufficient to elevate circulating AEA concentrations.

An interesting recent study examined circulating endocannabinoid concentrations in individuals who were isolated from family and friends for more than 500 days in a study simulating a trip to Mars (Yi et al, 2016). Individuals in this condition exhibited significant reductions in positive emotions and increased SNS activation. Circulating concentrations of 2-AG but not AEA were significantly reduced at the end of this significant, chronic stress. 2-AG concentrations were significantly, positively correlated with EEG alpha activity (which was suppressed by the isolation) and significantly, negatively correlated with circulating cortisol. These very interesting findings suggest that $2-A G$ is brain-derived and driven by excitatory signaling, which is consistent with considerable data that glutamate increases 2-AG synthesis (Hillard, 2015). These findings are also consistent with the role of $2-\mathrm{AG}$ to reduce HPA axis activation (Hillard et al, 2016). It is interesting that circulating 2-AG concentrations and measures of positive emotion were not associated in this study, given the evidence below that 2-AG has been found in other studies to be negatively associated with symptoms of depression.

\section{CIRCULATING ENDOCANNABINOIDS AND REWARD, ANXIETY AND COGNITION}

As has been discussed in preceding sections, CB1R signaling is involved in regulation of mood; modulates reward seeking behavior and hedonia; and is involved in behavioral responses to threat and stress. Some of the earliest studies 
in which circulating endocannabinoids were measured examined their relationships to indices of mood, anxiety and perception. These studies have the underlying assumption that circulating concentrations are affected by synaptic endocannabinoid tone, particularly in limbic brain regions. However, the only preclinical study that has tested this directly disputes this assumption (Hill et al, 2008a). In this study, rats exposed to chronic, unpredictable stress exposure had reduced endocannabinoid concentrations throughout the limbic regions of the brain, while plasma concentrations of AEA and 2-AG were significantly increased. However, the data that have come from human studies have largely found correlations between circulating endocannabinoids and measures of mood and anxiety in particular, suggesting that CNS function is somehow translated into alterations in circulating endocannabinoids.

\section{Endocannabinoids and Anxiety}

Several studies have found that circulating AEA concentrations are inversely related to both cognitive and somatic measures of anxiety (Dlugos et al, 2012; Hill et al, 2008c). In accordance with these data, carriers of FAAH C385A have significantly increased circulating AEA concentrations, and anxiety evoked by guided imagery of their trauma decayed more quickly than those homozygous for $\mathrm{C}$ at this position (Spagnolo et al, 2016). However, circulating endocannabinoids were not altered by touch massage, a procedure that produced a significant reduction in feelings of anxiety, although concentrations of PEA were significantly increased by this procedure (Lindgren et al, 2015).

Circulating endocannabinoids are altered in individuals diagnosed with post-traumatic stress disorder (PTSD). In particular, circulating concentrations of 2-AG are significantly lower in individuals with PTSD that occurred as a result of the World Trade Center attacks (Hill et al, 2013). The 2-AG decrease remained significant after correction for sex, alcohol use, and depression. Significantly lower circulating 2-AG concentrations without a difference in AEA were also found in a study of individuals with PTSD as a result of childhood sexual abuse compared to controls (Schaefer et al, 2014). On the other hand, hair OEA concentrations were significantly reduced in war survivors suffering from PTSD compared to survivors without the diagnosis and strongly, negatively correlated with symptom severity (Wilker et al, 2016). It is possible that measurement in the hair provides a more stable and reliable measurement, particularly for a chronic disorder, than a single time point measurement in the blood.

A few observations from these studies shed light on the possible relationships between circulating endocannabinoids and symptoms of PTSD. Although no group effects were identified, AEA concentrations were significantly, negatively associated with the number of intrusive symptoms in those with chronic PTSD (Hill et al, 2013). A study of alcoholics with PTSD found that the FAAH C385A SNP is associated with reduced hyperarousal (Spagnolo et al, 2016).
On the other hand, a study of war refugees with average scores of greater than 90 on the clinical administered PTSD scale (CAPS) and on average more than eight episodes of trauma exhibited significantly increased concentrations of both 2-AG and AEA compared to trauma-exposed individuals without PTSD and controls (Hauer et al, 2013). The contrast between these data and the other studies suggests that the amount of distress, not just the diagnosis of PTSD, could be an important determinant of endocannabinoid regulation.

\section{Endocannabinoids, Reward and Depression}

As was discussed above, increased circulating 2-AG concentrations are associated with enhanced hedonic food consumption, perhaps as a result of CB1R-mediated activation of reward seeking. Exercise has reported beneficial effects on mood, feelings of vigor, and anxiety, which are effects mediated by the CNS. Exercise-induced increases in AEA are significantly positively correlated with increased positive affect on the Positive and Negative Affect Schedule (PANAS) in one study (Raichlen et al, 2012), suggesting that recruitment of AEA-mediated signaling could contribute to the rewarding or reinforcing effects of exercise. Exerciseinduced increases in AEA are positively correlated with circulating concentrations of BDNF, which is also associated with elevation of mood (Heyman et al, 2012b).

Several studies have examined the acute effects of drugs that are associated with increased pleasurable feelings on circulating endocannabinoid concentrations. Consumption of $250 \mathrm{ml}$ of red wine with low sugar content resulted in reductions in AEA and 2-AG at 20 and $45 \mathrm{~min}$ after consumption, respectively (Feuerecker et al, 2012a). Healthy volunteers receiving an intravenous dose of $0.1 \mathrm{mg} / \mathrm{kg}$ THC responded with small increases in both 2-AG and AEA in the plasma at $30 \mathrm{~min}$, followed by marked reductions in both $5 \mathrm{~h}$ after the THC administration (Thieme et al, 2014). The effects of THC are particularly interesting as they suggest that the endocannabinoid system is regulated by cannabinoid receptor ligand concentrations, so that endocannabinoid concentrations are reduced in the face of exogenous agonist consumption.

Guided imagery procedures that produce alcohol desire and craving in social drinkers increase circulating concentrations of AEA, which were positively correlated with alcohol craving and increased heart rate (Mangieri et al, 2009). Importantly, the relationship between AEA and alcohol craving is lost in recently abstinent alcoholics, suggesting that endocannabinoid signaling within the reward circuit is dysregulated during abstinence. Baseline concentrations of AEA in the circulation were found to be significantly lower in abstinent alcoholics than social drinkers as well.

Interestingly, circulating AEA concentrations are also significantly lower in runners who meet criteria for exercise dependence compared to runners who carry out similar amounts of activity but do not exhibit exercise dependence 
(Fergusson and Boden, 2008). Individuals who met criteria for exercise dependence exhibit both greater mood disturbance and significantly lower basal levels of AEA when deprived of exercise than runners who do not exhibit exercise dependence (Antunes et al, 2016). While these data suggest deficient endocannabinoid signaling could contribute to dysphoria during abstinence, resumption of exercise resulted in elevation of mood without an increase in circulating AEA, which does not support this hypothesis. A study that investigated a large number of NAEs and monacylglycerols (MAGs) in plasma from abstinent cocaine addicts found NAEs were increased while MAGs were decreased (Pavon et al, 2013). However, neither AEA nor 2-AG were affected specifically in this study.

Several studies have found that circulating concentrations of both 2-AG and AEA are significantly altered in women diagnosed with depression. 2-AG concentrations were significantly lower in those newly diagnosed with major depression compared to controls with a significant, negative relationship between circulating $2-\mathrm{AG}$ and the duration of depressive symptoms (Hill et al, 2008c), which suggests the hypothesis that endocannabinoid deficiency contributes to depressive symptoms. Interestingly, AEA concentrations were increased in women diagnosed with minor depression, which the authors argued could be a compensatory mechanism to maintain elevated mood. In a second study of depressed women, baseline concentrations of both AEA and 2-AG were significantly lower than in controls (Hill et al, 2009b). Interestingly, 2-AG mobilization in response to the TSST was not different between control and depressed women (Hill et al, 2009b), suggesting that the mechanisms involved in the endocannabinoid response to acute stress and their role in depression are different. A study of individuals undergoing HCT found a significant, negative association between circulating 2-AG concentrations and depressive symptoms (Knight et al, 2015). On the other hand, a study of patients with osteoarthritis found that circulating 2-AG concentrations were significantly, positively associated with depression scores on the Hospital Anxiety and Depression Scale and negatively correlated with memory performance scores (La Porta et al, 2014). More work needs to be done to determine whether circulating endocannabinoid concentrations are related to specific depression symptoms or clusters of symptoms.

\section{Endocannabinoids and cognition}

Cannabis use in humans is associated with impaired executive function, including reduced behavioral flexibility (Ramaekers et al, 2006). A study in 150 healthy women showed a significant, negative correlation between 2-AG and cognitive flexibility performance assessed using the Wisconsin Card Sorting Test (WCST) (Fagundo et al, 2013), which is consistent with the hypothesis that excessive $\mathrm{CB} 1 \mathrm{R}$ activation, likely in the prefrontal cortex, reduces executive functioning. On the other hand, the same study found a positive correlation between circulating AEA concentrations and behavioral flexibility in both the WCST and the Iowa Gambling Task.

The roles of cannabinoids and endocannabinoid signaling in memory formation, retrieval and extinction have been studied extensively in preclinical models (Kruk-Slomka et al, 2016). While it is clear that memory is regulated by CB1R signaling, there is considerable variability in pharmacological studies that are likely related to dose, timing and differences in model systems. As noted above, circulating 2-AG concentrations are significantly, negatively correlated with memory in individuals with osteoporosis (La Porta et al, 2014). On the other hand, plasma 2-AG concentrations are significantly higher in individuals diagnosed with Alzheimer's Disease $(\mathrm{AD})$ compared to matched controls and are positively correlated with memory and attention in those with AD (Altamura et al, 2015). Yet another study found no differences in circulating endocannabinoid concentrations between patients with AD and controls (Koppel et al, 2009). The general anesthetic, propofol, has efficacy as a FAAH inhibitor and elevates brain AEA concentrations in mice (Patel et al, 2003). In rats, propofol treatment after training in an inhibitory avoidance task significantly increased latencies $48 \mathrm{~h}$ later, which is consistent with stronger memory consolidation (Hauer et al, 2011). This effect of propofol was blocked by rimonabant, consistent with a CB1R-mediated enhancement of memory. However, humans tend to exhibit amnesia with propofol treatment (Pryor et al, 2015), and humans do not exhibit an increase in circulating AEA after propofol treatment (Jarzimski et al, 2012; Schelling et al, 2006) so whether this mechanism is operative remains to be determined.

Cognitive deficits are a core symptom of schizophrenia and the degree of cognitive deficiency is a primary factor in functional impairment (Green et al, 2000). There is evidence that chronic, heavy use of cannabis is associated with some of the cognitive deficits in schizophrenia (Solowij and Michie, 2007), which suggests the hypothesis that endocannabinoid signaling is dysregulated in schizophrenia. Indeed, concentrations of AEA in the cerebrospinal fluid (CSF) of first episode schizophrenics are very significantly higher than control (Leweke et al, 1999). But contrary to the hypothesis that dysregulated endocannabinoid signaling contributes to disease symptoms, CSF concentrations of AEA are negatively correlated with psychotic symptoms in unmedicated patients (Giuffrida et al, 2004). Similarly, individuals in the initial, prodromal state of psychosis with the lowest CSF AEA concentrations had the highest risk for converting to a full psychotic episode (Koethe et al, 2009). These findings suggest the hypothesis that elevation of CSF AEA reflects a beneficial recruitment of CNS AEA signaling. No differences in circulating AEA were detected between schizophrenics and controls in which robust differences in CSF concentrations were found (Leweke et al, 2007) and in another study (Desfosses et al, 2012). However, other studies have found increased circulating AEA concentrations in schizophrenics compared to controls (De Marchi et al, 2003; Potvin et al, 2008). Serum AEA concentrations were increased in 
response to treatment with cannabidiol, which also alleviated the symptoms of schizophrenia (Leweke et al, 2012). Circulating AEA and 2-AG concentrations are significantly higher in patients diagnosed with borderline personality disorder, a psychiatric disorder that has some of the positive symptoms of schizophrenia, than controls (Schaefer et al, 2014).

\section{CIRCULATING ENDOCANNABINOIDS AND PAIN}

Preclinical and human studies support the overall hypothesis that $\mathrm{CB} 1 \mathrm{R}$ and $\mathrm{CB} 2 \mathrm{R}$ activation both result in reduced pain perception (Piomelli et al, 2014). In addition, data are emerging that PEA is anti-inflammatory and analgesic (Mattace Raso et al, 2014). On the other hand, there are mechanisms by which both 2-AG and AEA could increase pain sensation. 2-AG has been hypothesized to serve as a precursor for arachidonic acid (Kozak et al, 2000) and is converted by COX-2 to oxygenated products that increase pain perception (Hu et al, 2008); and AEA activates pro-nociceptive TRPV1 channels (Zygmunt et al, 1999). Thus, endocannabinoids have the potential to increase or decrease the perception of pain, depending upon the mechanism of action.

Increases in circulating AEA concentrations occur in patients with chronic pain syndromes, such as fibromyalgia (Kaufmann et al, 2008) and complex regional pain syndrome (Kaufmann et al, 2009) when compared to controls without pain. A relatively common single nucleotide polymorphism in the gene for FAAH that results in elevated circulating concentrations of AEA (rs324420) (Sipe et al, 2010) is associated with lower sensitivity to cold pain (Cajanus et al, 2016), suggesting that higher circulating AEA concentrations seen in chronic pain could reduce pain perception.

Increases in circulating 2-AG concentrations have also been reported in chronic pain, including neuromyelitis optica (NMO) (Pellkofer et al, 2013) and osteoarthritis (La Porta et al, 2015). In NMO, 2-AG is negatively correlated with mechanical pain thresholds, suggesting an analgesic role (Pellkofer et al, 2013). However, in osteoarthritis, 2-AG is positively correlated with knee pain, suggesting that it contributes to pain perception (La Porta et al, 2015).

In a dietary intervention study in chronic headache sufferers, increased omega- 3 and reduced omega- 6 fatty acid consumption was used to alter the circulating concentrations of AEA and 2-AG, which were both reduced by this intervention (Ramsden et al, 2015). Circulating concentrations of AEA and 2-AG were both significantly, positively correlated with the numbers of daily severe headaches, suggesting roles in the etiology of headache. Interestingly, this dietary intervention produces very significant increases in the ethanolamide and 2-acylglycerol of docosahexaenoic acid (DHA), both of which were inversely correlated with the number of severe daily headaches.

Exercise reduces the perception of pain, termed exerciseinduced hypoalgesia (EIH), which occurs through both opioid and non-opioid mechanisms (Koltyn, 2000). In an early review, Dietrich and McDaniel speculated that endocannabinoids could be responsible for non-opioid EIH (Dietrich and McDaniel, 2004). In support of this hypothesis, Koltyn and colleagues demonstrated that brief periods of isometric exercise produce non-opioid-dependent $\mathrm{EIH}$ and a very significant increase in circulating 2-AG concentrations (Koltyn et al, 2014). Interestingly, correlational analyses did not support a significant relationship between circulating 2-AG (or AEA) concentrations and any measure of pain responsivity. However, CB1R are densely expressed on peripheral nerve terminals of A-delta and C primary afferents innervating skeletal muscle (Hohmann and Herkenham, 1999), so it is possible that the endocannabinoids increased by muscle activity act locally to produce EIH. This could explain the lack of correlation between endocannabinoids in the circulation and EIH.

\section{SUMMARY AND FUTURE STUDIES}

While our current state of understanding of the role of the endocannabinoid system in humans has been enhanced by measurement of circulating endocannabinoids, many of the studies have examined only a few individuals and only single time points. Recent studies showing that 2-AG is significantly circadian and that there are differences in the response to stress among men and women and, potentially, among races indicate that large, comprehensive studies that include a diverse population of individuals will provide the best data. Careful consideration of the time of sampling, and better yet, determination of endocannabinoids at multiple time points or after a stress or exercise challenge could provide important information that cannot be obtained at a single time point.

An important question that is particularly related to the studies of the relationships between circulating endocannabinoids and psychiatric disorders is whether circulating endocannabinoids are a biomarker for brain endocannabinoid signaling. Aside from the correlations and associations described above, the available data suggest that brain concentrations are not related to peripheral concentrations in a straightforward manner. For example, CSF AEA concentrations are increased multifold without consistent changes in their circulating concentrations, which indicates that overflow might not be consistent, particularly from the brain (Jumpertz et al, 2011). In addition, a preclinical study that examined both brain and peripheral endocannabinoids found no relationship between brain and plasma concentrations of 2-AG or AEA in chronically stressed rats (Hill et al, 2008b). It is possible that CNS function is translated into circulating endocannabinoids through changes in neuronal or endocrine outputs that drive alterations in endocannabinoid synthesis or degradation in peripheral tissues.

In my opinion, it is time for preclinical studies, where the relationships among circulating endocannabinoids and tissues can be determined, to catch up to the data obtained in 
humans. Preclinical models can help us to understand the extent to which circulating concentrations of endocannabinoids are related to brain concentrations; the degree to which circulating concentrations represent signaling pools; and, most importantly, whether or not circulating endocannabinoid concentrations can function as biomarkers of endocannabinoid signaling status. Currently, the answers to these fundamental questions are unknown.

\section{FUNDING AND DISCLOSURE}

The author declares no conflict of interest.

\section{ACKNOWLEDGMENTS}

The author was supported during the writing of this review by NIH grants DA038663, DA042205, DA41202 and MH102838.

\section{REFERENCES}

Abdulnour J, Yasari S, Rabasa-Lhoret R, Faraj M, Petrosino S, Piscitelli F et al (2014). Circulating endocannabinoids in insulin sensitive vs. insulin resistant obese postmenopausal women. A MONET group study. Obesity (Silver Spring) 22: 211-216.

Allen AP, Kennedy PJ, Cryan JF, Dinan TG, Clarke G (2014). Biological and psychological markers of stress in humans: focus on the Trier Social Stress Test. Neurosci Biobehav Rev 38: 94-124.

Altamura C, Ventriglia M, Martini MG, Montesano D, Errante Y, Piscitelli F et al (2015). Elevation of plasma 2-arachidonoylglycerol levels in Alzheimer's disease patients as a potential protective mechanism against neurodegenerative decline. $J$ Alzheimers Dis 46: 497-506.

Amoako AA, Marczylo TH, Lam PM, Willets JM, Derry A, Elson $J$ et al (2010). Quantitative analysis of anandamide and related acylethanolamides in human seminal plasma by ultra performance liquid chromatography tandem mass spectrometry. J Chromatogr B Analyt Technol Biomed Life Sci 878: 3231-3237.

Antunes HK, Leite GS, Lee KS, Barreto AT, Santos RV, Souza Hde S et al (2016). Exercise deprivation increases negative mood in exercise-addicted subjects and modifies their biochemical markers. Physiol Behav 156: 182-190.

Argueta DA, DiPatrizio NV (2017). Peripheral endocannabinoid signaling controls hyperphagia in western diet-induced obesity. Physiol Behav 171: 32-39.

Balaban CD (1999). Vestibular autonomic regulation (including motion sickness and the mechanism of vomiting). Curr Opin Neurol 12: 29-33.

Batkai S, Osei-Hyiaman D, Pan H, El-Assal O, Rajesh M, Mukhopadhyay P et al (2007). Cannabinoid-2 receptor mediates protection against hepatic ischemia/ reperfusion injury. FASEB J 21: 1788-1800.

Benedict C, Brooks SJ, O'Daly OG, Almen MS, Morell A, Aberg Ket al (2012). Acute sleep deprivation enhances the brain's response to hedonic food stimuli: an fMRI study. J Clin Endocrinol Metab 97: E443-E447.

Bermudez-Silva FJ, Cardinal P, Cota D (2012). The role of the endocannabinoid system in the neuroendocrine regulation of energy balance. J Psychopharmacol 26: 114-124.

Blankman JL, Simon GM, Cravatt BF (2007). A comprehensive profile of brain enzymes that hydrolyze the endocannabinoid 2-arachidonoylglycerol. Chem Biol 14: 1347-1356.

Bluher M, Engeli S, Kloting N, Berndt J, Fasshauer M, Batkai S et al (2006). Dysregulation of the peripheral and adipose tissue endocannabinoid system in human abdominal obesity. Diabetes 55: 3053-3060.

Bojesen IN, Hansen HS (2003). Binding of anandamide to bovine serum albumin. J Lipid Res 44: 1790-1794.

Bowles NP, Karatsoreos IN, Li X, Vemuri VK, Wood JA, Li Z et al (2015). A peripheral endocannabinoid mechanism contributes to glucocorticoid-mediated metabolic syndrome. Proc Natl Acad Sci USA 112: 285-290.

Breunig E, Czesnik D, Piscitelli F, Di Marzo V, Manzini I, Schild D (2010). Endocannabinoid modulation in the olfactory epithelium. Results Probl Cell Differ 52: 139-145.

Brisbois TD, de Kock $1 \mathrm{H}$, Watanabe SM, Mirhosseini M, Lamoureux DC, Chasen M et al (2011). Delta-9-tetrahydrocannabinol may palliate altered chemosensory perception in cancer patients: results of a randomized, double-blind, placebocontrolled pilot trial. Ann Oncol 22: 2086-2093.

Cable JC, Tan GD, Alexander SP, O'Sullivan SE (2014). The effects of obesity, diabetes and metabolic syndrome on the hydrolytic enzymes of the endocannabinoid system in animal and human adipocytes. Lipids Health Dis 13: 43.

Cajanus K, Holmstrom EJ, Wessman M, Anttila V, Kaunisto MA, Kalso E (2016). Effect of endocannabinoid degradation on pain: role of FAAH polymorphisms in experimental and postoperative pain in women treated for breast cancer. Pain 157: 361-369.

Caraceni P, Viola A, Piscitelli F, Giannone F, Berzigotti A, Cescon M et al (2010). Circulating and hepatic endocannabinoids and endocannabinoid-related molecules in patients with cirrhosis. Liver Int 30: 816-825.

Cedernaes J, Fanelli F, Fazzini A, Pagotto U, Broman JE, Vogel H et al (2016). Sleep restriction alters plasma endocannabinoids concentrations before but not after exercise in humans. Psychoneuroendocrinology 74: 258-268.

Chen CY, Bonham AC, Dean C, Hopp FA, Hillard CJ, Seagard JL (2010). Retrograde release of endocannabinoids inhibits presynaptic GABA release to second-order baroreceptive neurons in NTS. Auton Neurosci 158: 44-50.

Chouker A, Kaufmann I, Kreth S, Hauer D, Feuerecker M, Thieme D et al (2010). Motion sickness, stress and the endocannabinoid system. PLOS ONE 5: e10752.

Copinschi G, Turek FW, Van Cauter E (2010). Endocrine rythms, the sleep-wake cycle and biological clocks. In: LJ J, LJ D (eds). Endocrinology 6th edn. ElsevierSaunders: Philadelphia. pp 199-229.

Cota D, Tschop MH, Horvath TL, Levine AS (2006). Cannabinoids, opioids and eating behavior: The molecular face of hedonism? Brain Res Brain Res Rev 51: 85-107.

Cote M, Matias I, Lemieux I, Petrosino S, Almeras N, Despres JP et al (2007). Circulating endocannabinoid levels, abdominal adiposity and related cardiometabolic risk factors in obese men. Int J Obes (Lond) 31: 692-699.

Cravatt BF, Giang DK, Mayfield SP, Boger DL, Lerner RA, Gilula NB (1996). Molecular characterization of an enzyme that degrades neuromodulatory fatty-acid amides. Nature 384: 83-87.

Crespillo A, Suarez J, Bermudez-Silva FJ, Rivera P, Vida M, Alonso M et al (2011). Expression of the cannabinoid system in muscle: effects of a high-fat diet and CB1 receptor blockade. Biochem J 433: 175-185.

D'Eon TM, Pierce KA, Roix JJ, Tyler A, Chen H, Teixeira SR (2008). The role of adipocyte insulin resistance in the pathogenesis of obesity-related elevations in endocannabinoids. Diabetes 57: 1262-1268.

D'Souza DC, Pittman B, Perry E, Simen A (2009). Preliminary evidence of cannabinoid effects on brain-derived neurotrophic factor (BDNF) levels in humans. Psychopharmacology (Berl) 202: 569-578.

Danilenko KV, Cajochen C, Wirz-Justice A (2003). Is sleep per se a zeitgeber in humans? J Biol Rhythms 18: 170-178.

Dantzer R, O'Connor JC, Freund GG, Johnson RW, Kelley KW (2008). From inflammation to sickness and depression: when the immune system subjugates the brain. Nat Rev Neurosci 9: 46-56.

De Luca MA, Solinas M, Bimpisidis Z, Goldberg SR, Di Chiara G (2012). Cannabinoid facilitation of behavioral and biochemical hedonic taste responses. Neuropharmacology 63: 161-168.

De Marchi N, De Petrocellis L, Orlando P, Daniele F, Fezza F, Di Marzo V (2003). Endocannabinoid signalling in the blood of patients with schizophrenia. Lipids Health Dis 2: 5

Dean C (2011). Cannabinoid and GABA modulation of sympathetic nerve activity and blood pressure in the dorsal periaqueductal gray of the rat. Am J Physiol Regul Integr Comp Physiol 301: R1765-R1772.

Desfosses J, Stip E, Bentaleb LA, Lipp O, Chiasson JP, Furtos A et al (2012). Plasma endocannabinoid alterations in individuals with substance use disorder are dependent on the 'Mirror Effect' of Schizophrenia. Front Psychiatry 3: 85.

Di Marzo V, Bisogno T, De Petrocellis L, Melck D, Orlando P, Wagner JA et al (1999). Biosynthesis and inactivation of the endocannabinoid 2- arachidonoylglycerol in circulating and tumoral macrophages. Eur J Biochem 264: 258-267.

Di Marzo V, Goparaju SK, Wang L, Liu J, Batkai S, Jarai Z et al (2001). Leptinregulated endocannabinoids are involved in maintaining food intake. Nature 410 : 822-825.

Di Marzo V, Verrijken A, Hakkarainen A, Petrosino S, Mertens I, Lundbom N et al (2009). Role of insulin as a negative regulator of plasma endocannabinoid levels in obese and nonobese subjects. Eur J Endocrinol 161: 715-722.

Di S, Malcher-Lopes R, Marcheselli VL, Bazan NG, Tasker JG (2005). Rapid glucocorticoid-mediated endocannabinoid release and opposing regulation of glutamate and GABA inputs to hypothalamic magnocellular neurons. Endocrinology 146: 4292-4301.

Dietrich A, McDaniel WF (2004). Endocannabinoids and exercise. Br J Sports Med 38: 536-541. 
Dipatrizio NV, Astarita G, Schwartz G, Li X, Piomelli D (2011). From the Cover: Endocannabinoid signal in the gut controls dietary fat intake. Proc Natl Acad Sci USA 108: 12904-12908.

Dlugos A, Childs E, Stuhr KL, Hillard CJ, de Wit H (2012). Acute stress increases circulating anandamide and other $\mathrm{N}$-acylethanolamines in healthy humans. Neuropsychopharmacology 37: 2416-2427.

Dotsey E, Ushach I, Pone E, Nakajima R, Jasinskas A, Argueta DA et al (2017). Transient Cannabinoid Receptor 2 Blockade during Immunization Heightens Intensity and Breadth of Antigen-specific Antibody Responses in Young and Aged mice. Sci Rep 7: 42584.

Engeli S, Bluher M, Jumpertz R, Wiesner T, Wirtz H, Bosse-Henck A et al (2012). Circulating anandamide and blood pressure in patients with obstructive sleep apnea. J Hypertens 30: 2345-2351.

Engeli S, Bohnke J, Feldpausch M, Gorzelniak K, Janke J, Batkai S et al (2005). Activation of the peripheral endocannabinoid system in human obesity. Diabetes 54: 2838-2843.

Enzi G, Gasparo M, Biondetti PR, Fiore D, Semisa M, Zurlo F (1986). Subcutaneous and visceral fat distribution according to sex, age, and overweight, evaluated by computed tomography. Am J Clin Nutr 44: 739-746.

Fagundo AB, de la Torre R, Jimenez-Murcia S, Aguera Z, Pastor A, Casanueva FF et al (2013). Modulation of the endocannabinoids $\mathrm{N}$-arachidonoylethanolamine (AEA) and 2-arachidonoylglycerol (2-AG) on executive functions in humans. PLoS ONE 8: e66387.

Felton SJ, Kendall AC, Almaedani AF, Urquhart P, Webb AR, Kift R et al (2017). Serum endocannabinoids and $\mathrm{N}$-acyl ethanolamines and the influence of simulated solar UVR exposure in humans in vivo. Photochem Photobiol Sci in press 16: 564-574.

Fergusson DM, Boden JM (2008). Cannabis use and adult ADHD symptoms. Drug Alcohol Depend 95: 90-96.

Fernandez-Aranda F, Sauchelli S, Pastor A, Gonzalez ML, de la Torre R, Granero R et al (2014). Moderate-vigorous physical activity across body mass index in females: moderating effect of endocannabinoids and temperament. PLOS ONE 9: e104534.

Fernandez-Rodriguez CM, Romero J, Petros TJ, Bradshaw H, Gasalla JM, Gutierrez ML et al (2004). Circulating endogenous cannabinoid anandamide and portal, systemic and renal hemodynamics in cirrhosis. Liver Int 24: 477-483.

Feuerecker M, Hauer D, Gresset T, Lassas S, Kaufmann I, Vogeser M et al (2012a). Effect of an acute consumption of a moderate amount of ethanol on plasma endocannabinoid levels in humans. Alcohol Alcohol 47: 226-232.

Feuerecker M, Hauer D, Toth R, Demetz F, Holzl J, Thiel M et al (2012b). Effects of exercise stress on the endocannabinoid system in humans under field conditions. Eur J Appl Physiol 112: 2777-2781.

Fu J, Astarita G, Gaetani S, Kim J, Cravatt BF, Mackie K et al (2007). Food intake regulates oleoylethanolamide formation and degradation in the proximal small intestine. J Biol Chem 282: 1518-1528.

Fu J, Gaetani S, Oveisi F, Lo Verme J, Serrano A, Rodriguez De Fonseca F et al (2003). Oleylethanolamide regulates feeding and body weight through activation of the nuclear receptor PPAR-alpha. Nature 425: 90-93.

Galiegue S, Mary S, Marchand J, Dussossoy D, Carriere D, Carayon P et al (1995). Expression of central and peripheral cannabinoid receptors in human immune tissues and leukocyte subpopulations. Eur J Biochem 232: 54-61.

Gasperi V, Ceci R, Tantimonaco M, Talamonti E, Battista N, Parisi A et al (2014). The fatty acid amide hydrolase in lymphocytes from sedentary and active subjects. Med Sci Sports Exerc 46: 24-32.

Gatta-Cherifi B, Matias I, Vallee M, Tabarin A, Marsicano G, Piazza PV et al (2012). Simultaneous postprandial deregulation of the orexigenic endocannabinoid anandamide and the anorexigenic peptide $Y Y$ in obesity. Int $J$ Obes (Lond) 36: 880-885.

Gauthier KM, Baewer DV, Hittner S, Hillard CJ, Nithipatikom K, Reddy DS et al (2005). Endothelium-derived 2-arachidonylglycerol: an intermediate in vasodilatory eicosanoid release in bovine coronary arteries. Am J Physiol Heart Circ Physiol 288: H1344-H1351.

Ghafouri N, Ghafouri B, Larsson B, Stensson N, Fowler CJ, Gerdle B (2013). Palmitoylethanolamide and stearoylethanolamide levels in the interstitium of the trapezius muscle of women with chronic widespread pain and chronic neck-shoulder pain correlate with pain intensity and sensitivity. Pain 154: 1649-1658.

Giuffrida A, Leweke FM, Gerth CW, Schreiber D, Koethe D, Faulhaber J et al (2004). Cerebrospinal anandamide levels are elevated in acute schizophrenia and are inversely correlated with psychotic symptoms. Neuropsychopharmacology 29: 2108-2114.

Giuffrida A, Rodriguez de Fonseca F, Nava F, Loubet-Lescoulie P, Piomelli D (2000). Elevated circulating levels of anandamide after administration of the transport inhibitor, AM404. Eur J Pharmacol 408: 161-168.
Goparaju SK, Ueda N, Yamaguchi H, Yamamoto S (1998). Anandamide amidohydrolase reacting with 2-arachidonoylglycerol, another cannabinoid receptor ligand. FEBS Lett 422: 69-73.

Gouveia-Figueira S, Nording ML (2014). Development and validation of a sensitive UPLC-ESI-MS/MS method for the simultaneous quantification of 15 endocannabinoids and related compounds in milk and other biofluids. Anal Chem 86: 1186-1195.

Gray JM, Vecchiarelli HA, Morena M, Lee TT, Hermanson DJ, Kim AB et al (2015). Corticotropin-releasing hormone drives anandamide hydrolysis in the amygdala to promote anxiety. J Neurosci 35: 3879-3892.

Green MF, Kern RS, Braff DL, Mintz J (2000). Neurocognitive deficits and functional outcome in schizophrenia: are we measuring the 'right stuff'? Schizophr Bull 26 119-136.

Guzman M, Lo Verme J, Fu J, Oveisi F, Blazquez C, Piomelli D (2004). Oleoylethanolamide stimulates lipolysis by activating the nucelar receptor PPAR-alpha. J Biol Chem 279: 27849-27854.

Hanlon EC, Tasali E, Leproult R, Stuhr KL, Doncheck E, de Wit H et al (2015). Circadian rhythm of circulating levels of the endocannabinoid 2-arachidonoylglycerol. J Clin Endocrinol Metab 100: 220-226.

Hanlon EC, Tasali E, Leproult R, Stuhr KL, Doncheck E, de Wit H et al (2016). Sleep restriction enhances the daily rhythm of circulating levels of endocannabinoid 2-arachidonoylglycerol. Sleep 39: 653-664.

Hauer D, Ratano P, Morena M, Scaccianoce S, Briegel I, Palmery M et al (2011). Propofol enhances memory formation via an interaction with the endocannabinoid system. Anesthesiology 114: 1380-1388.

Hauer D, Schelling G, Gola H, Campolongo P, Morath J, Roozendaal B et al (2013). Plasma concentrations of endocannabinoids and related primary fatty acid amides in patients with post-traumatic stress disorder. PLOS ONE 8: e62741.

Heyman E, Gamelin FX, Aucouturier J, Di Marzo V (2012a). The role of the endocannabinoid system in skeletal muscle and metabolic adaptations to exercise: potential implications for the treatment of obesity. Obes Rev 13: 1110-1124.

Heyman E, Gamelin FX, Goekint M, Piscitelli F, Roelands B, Leclair E et al (2012b). Intense exercise increases circulating endocannabinoid and BDNF levels in humans-possible implications for reward and depression. Psychoneuroendocrinology 37: 844-851.

Hill MN, Bierer LM, Makotkine I, Golier JA, Galea S, McEwen BS et al (2013). Reductions in circulating endocannabinoid levels in individuals with post-traumatic stress disorder following exposure to the World Trade Center attacks. Psychoneuroendocrinology 38: 2952-2961.

Hill MN, Carrier EJ, Ho WS, Shi L, Patel S, Gorzalka BB et al (2008a). Prolonged glucocorticoid treatment decreases cannabinoid $\mathrm{CB} 1$ receptor density in the hippocampus. Hippocampus 18: 221-226.

Hill MN, Carrier EJ, McLaughlin RJ, Morrish AC, Meier SE, Hillard CJ et al (2008b). Regional alterations in the endocannabinoid system in an animal model of depression: effects of concurrent antidepressant treatment. J Neurochem 106 : 2322-2336.

Hill MN, Karatsoreos IN, Hillard CJ, McEwen BS (2010). Rapid elevations in limbic endocannabinoid content by glucocorticoid hormones in vivo. Psychoneuroendocrinology 35: 1333-1338.

Hill MN, McLaughlin RJ, Morrish AC, Viau V, Floresco SB, Hillard CJ et al (2009a). Suppression of amygdalar endocannabinoid signaling by stress contributes to activation of the hypothalamic-pituitary-adrenal axis. Neuropsychopharmacology 34: 2733-2745.

Hill MN, McLaughlin RJ, Pan B, Fitzgerald ML, Roberts CJ, Lee $\Pi$ et al (2011). Recruitment of prefrontal cortical endocannabinoid signaling by glucocorticoids contributes to termination of the stress response. J Neurosci 31: 10506-10515.

Hill MN, Miller GE, Carrier EJ, Gorzalka BB, Hillard CJ (2009b). Circulating endocannabinoids and $\mathrm{N}$-acyl ethanolamines are differentially regulated in major depression and following exposure to social stress. Psychoneuroendocrinology 34: 1257-1262.

Hill MN, Miller GE, Ho WS, Gorzalka BB, Hillard CJ (2008c). Serum endocannabinoid content is altered in females with depressive disorders: a preliminary report. Pharmacopsychiatry 41: 48-53.

Hillard CJ (2014). Stress regulates endocannabinoid-CB1 receptor signaling. Semin Immunol 26: 380-388.

Hillard CJ (2015). The Endocannabinoid Signaling System in the CNS: A Primer. Int Rev Neurobiol 125: 1-47.

Hillard CJ, Beatka M, Sarvaideo J (2016). Endocannabinoid Signaling and the Hypothalamic-Pituitary-Adrenal Axis. Comprehens Physiol 7: 1-15.

Hillard CJ, Weinlander KM, Stuhr KL (2012). Contributions of endocannabinoid signaling to psychiatric disorders in humans: genetic and biochemical evidence. Neuroscience 204: 207-229.

Hindmarch CC, Ferguson AV (2016). Physiological roles for the subfornical organ: a dynamic transcriptome shaped by autonomic state. J Physiol 594: 1581-1589. 
Ho WS, Gardiner SM (2009). Acute hypertension reveals depressor and vasodilator effects of cannabinoids in conscious rats. Br J Pharmacol 156: 94-104.

Ho WV, Hill MN, Miller GE, Gorzalka BB, Hillard CJ (2012). Serum contents of endocannabinoids are correlated with blood pressure in depressed women. Lipids Health Dis 11: e32.

Hohmann AG, Herkenham M (1999). Localization of central cannabinoid CB1 receptor messenger RNA in neuronal subpopulations of rat dorsal root ganglia: a double-label in situ hybridization study. Neuroscience 90: 923-931.

Hu SS, Bradshaw HB, Chen JS, Tan B, Walker JM (2008). Prostaglandin E2 glycerol ester, an endogenous COX-2 metabolite of 2-arachidonoylglycerol, induces hyperalgesia and modulates NFkappaB activity. Br J Pharmacol 153: 1538-1549.

Hutchins-Wiese HL, Li Y, Hannon K, Watkins BA (2012). Hind limb suspension and long-chain omega-3 PUFA increase mRNA endocannabinoid system levels in skeletal muscle. J Nutr Biochem 23: 986-993.

Ishac EJ, Jiang L, Lake KD, Varga K, Abood ME, Kunos G (1996). Inhibition of exocytotic noradrenaline release by presynaptic cannabinoid CB1 receptors on peripheral sympathetic nerves. Br J Pharmacol 118: 2023-2028.

lyer MR, Cinar R, Katz A, Gao M, Erdelyi K, Jourdan T et al (2017). Design, Synthesis, and Biological Evaluation of Novel, Non-Brain-Penetrant, Hybrid Cannabinoid CB1R Inverse Agonist/Inducible Nitric Oxide Synthase (iNOS) Inhibitors for the Treatment of Liver Fibrosis. J Med Chem 60: 1126-1141.

Jarzimski C, Karst M, Zoerner AA, Rakers C, May M, Suchy MT et al (2012). Changes of blood endocannabinoids during anaesthesia: a special case for fatty acid amide hydrolase inhibition by propofol? Br J Clin Pharmacol 74: 54-59.

Jian W, Edom R, Weng N, Zannikos P, Zhang Z, Wang H (2010). Validation and application of an LC-MS/MS method for quantitation of three fatty acid ethanolamides as biomarkers for fatty acid hydrolase inhibition in human plasma. J Chromatogr B Analyt Technol Biomed Life Sci 878: 1687-1699.

Jones PJ, Lin L, Gillingham LG, Yang H, Omar JM (2014). Modulation of plasma $\mathrm{N}$-acylethanolamine levels and physiological parameters by dietary fatty acid composition in humans. J Lipid Res 55: 2655-2664.

Juan-Pico P, Fuentes E, Javier Bermudez-Silva F, Javier Diaz-Molina F, Ripoll C, Rodriguez de Fonseca F et al (2006). Cannabinoid receptors regulate $\mathrm{Ca}(2+)$ signals and insulin secretion in pancreatic beta-cell. Cell Calcium 39: 155-162.

Jumpertz R, Guijarro A, Pratley RE, Piomelli D, Krakoff J (2011). Central and peripheral endocannabinoids and cognate acylethanolamides in humans: association with race, adiposity, and energy expenditure. J Clin Endocrinol Metab 96: 787-791

Kaufmann I, Hauer D, Huge V, Vogeser M, Campolongo P, Chouker A et al (2009). Enhanced anandamide plasma levels in patients with complex regional pain syndrome following traumatic injury: a preliminary report. Eur Surg Res 43: 325-329.

Kaufmann I, Schelling G, Eisner C, Richter HP, Krauseneck T, Vogeser M et al (2008). Anandamide and neutrophil function in patients with fibromyalgia. Psychoneuroendocrinology 33: 676-685.

Keating C, Tilbrook AJ, Rossell SL, Enticott PG, Fitzgerald PB (2012). Reward processing in anorexia nervosa. Neuropsychologia 50: 567-575.

Khaspekov LG, Brenz Verca MS, Frumkina LE, Hermann H, Marsicano G, Lutz B (2004). Involvement of brain-derived neurotrophic factor in cannabinoid receptordependent protection against excitotoxicity. Eur J Neurosci 19: 1691-1698.

Kirkwood JS, Broeckling CD, Donahue S, Prenni JE (2016). A novel microflow LC-MS method for the quantitation of endocannabinoids in serum. J Chromatogr B Analyt Technol Biomed Life Sci 1033-1034: 271-277.

Knight JM, Szabo A, Zhao S, Lyness JM, Sahler OJ, Liesveld JL et al (2015). Circulating endocannabinoids during hematopoietic stem cell transplantation: A pilot study. Neurobiol Stress 2: 44-50.

Koethe D, Giuffrida A, Schreiber D, Hellmich M, Schultze-Lutter F, Ruhrmann S et al (2009). Anandamide elevation in cerebrospinal fluid in initial prodromal states of psychosis. Br J Psychiatry 194: 371-372.

Kola B, Farkas I, Christ-Crain M, Wittmann G, Lolli F, Amin F et al (2008). The orexigenic effect of ghrelin is mediated through central activation of the endogenous cannabinoid system. PLOS ONE 3: e1797.

Koltyn KF (2000). Analgesia following exercise: a review. Sports Med 29: 85-98.

Koltyn KF, Brellenthin AG, Cook DB, Sehgal N, Hillard C (2014). Mechanisms of exercise-induced hypoalgesia. J Pain 15: 1294-1304.

Koppel J, Bradshaw H, Goldberg TE, Khalili H, Marambaud P, Walker MJ et al (2009). Endocannabinoids in Alzheimer's disease and their impact on normative cognitive performance: a case-control and cohort study. Lipids Health Dis 8: 2.

Kozak KR, Rowlinson SW, Marnett LJ (2000). Oxygenation of the endocannabinoid, 2-arachidonylglycerol, to glyceryl prostaglandins by cyclooxygenase-2. J Biol Chem 275: 33744-33749.

Kruk-Slomka M, Dzik A, Budzynska B, Biala G (2016). Endocannabinoid system: the direct and indirect involvement in the memory and learning processes-a short review. Mol Neurobiol in press.
Krumbholz A, Anielski P, Reisch N, Schelling G, Thieme D (2013). Diagnostic value of concentration profiles of glucocorticosteroids and endocannabinoids in hair. Ther Drug Monit 35: 600-607.

Kurabayashi M, Takeyoshi I, Yoshinari D, Matsumoto K, Maruyama I, Morishita Y (2005). 2-Arachidonoylglycerol increases in ischemia-reperfusion injury of the rat liver. J Invest Surg 18: 25-31.

La Porta C, Bura SA, Llorente-Onaindia J, Pastor A, Navarrete F, Garcia-Gutierrez MS et al (2015). Role of the endocannabinoid system in the emotional manifestations of osteoarthritis pain. Pain 156: 2001-2012.

La Porta C, Bura SA, Negrete R, Maldonado R (2014). Involvement of the endocannabinoid system in osteoarthritis pain. Eur J Neurosci 39: 485-500.

Lam PM, Marczylo TH, Konje JC (2010). Simultaneous measurement of three $\mathrm{N}$-acylethanolamides in human bio-matrices using ultra performance liquid chromatography-tandem mass spectrometry. Anal Bioanal Chem 398: 2089-2097.

Leleu-Chavain N, Desreumaux P, Chavatte P, Millet R (2013). Therapeutical potential of $\mathrm{CB}(2)$ receptors in immune-related diseases. Curr Mol Pharmacol 6: 183-203.

Leweke FM, Giuffrida A, Koethe D, Schreiber D, Nolden BM, Kranaster L et al (2007). Anandamide levels in cerebrospinal fluid of first-episode schizophrenic patients: Impact of cannabis use. Schizophr Res 94: 29-36.

Leweke FM, Giuffrida A, Wurster U, Emrich HM, Piomelli D (1999). Elevated endogenous cannabinoids in schizophrenia. Neuroreport 10: 1665-1669.

Leweke FM, Piomelli D, Pahlisch F, Muhl D, Gerth CW, Hoyer C et al (2012). Cannabidiol enhances anandamide signaling and alleviates psychotic symptoms of schizophrenia. Trans/ Psychiatry 2: e94.

Lindgren L, Gouveia-Figueira S, Nording ML, Fowler CJ (2015). Endocannabinoids and related lipids in blood plasma following touch massage: a randomised, crossover study. BMC Res Notes 8: 504.

Liu YL, Connoley IP, Wilson CA, Stock MJ (2005). Effects of the cannabinoid CB1 receptor antagonist SR141716 on oxygen consumption and soleus muscle glucose uptake in Lep(ob)/Lep(ob) mice. Int J Obes Relat Metab Disord 29: 183-187.

Maeda N, Osanai T, Kushibiki M, Fujiwara T, Tamura Y, Oowada S et al (2009). Increased serum anandamide level at ruptured plaque site in patients with acute myocardial infarction. Fundam Clin Pharmacol 23: 351-357.

Mahler SV, Smith KS, Berridge KC (2007). Endocannabinoid hedonic hotspot for sensory pleasure: anandamide in nucleus accumbens shell enhances 'liking' of a sweet reward. Neuropsychopharmacology 32: 2267-2278.

Mangieri RA, Hong KI, Piomelli D, Sinha R (2009). An endocannabinoid signal associated with desire for alcohol is suppressed in recently abstinent alcoholics. Psychopharmacology (Berl) 205: 63-72.

Marazzi J, Kleyer J, Paredes JM, Gertsch J (2011). Endocannabinoid content in fetal bovine sera-unexpected effects on mononuclear cells and osteoclastogenesis. J Immunol Methods 373: 219-228.

Maresz K, Pryce G, Ponomarev ED, Marsicano G, Croxford JL, Shriver LP et al (2007). Direct suppression of CNS autoimmune inflammation via the cannabinoid receptor $\mathrm{CB} 1$ on neurons and $\mathrm{CB} 2$ on autoreactive $\mathrm{T}$ cells. Nat Med 13: 492-497.

Marsicano G, Goodenough S, Monory K, Hermann H, Eder M, Cannich A et al (2003). CB1 cannabinoid receptors and on-demand defense against excitotoxicity. Science 302: 84-88.

Marsland AL, McCaffery JM, Muldoon MF, Manuck SB (2010). Systemic inflammation and the metabolic syndrome among middle-aged community volunteers. Metabolism 59: 1801-1808.

Matias I, Gatta-Cherifi B, Tabarin A, Clark S, Leste-Lasserre T, Marsicano G et al (2012). Endocannabinoids measurement in human saliva as potential biomarker of obesity. PLOS ONE 7: e42399.

Matsuda K, Mikami Y, Takeda K, Fukuyama S, Egawa S, Sunamura M et al (2005). The cannabinoid 1 receptor antagonist, AM251, prolongs the survival of rats with severe acute pancreatitis. Tohoku J Exp Med 207: 99-107.

Mattace Raso G, Russo R, Calignano A, Meli R (2014). Palmitoylethanolamide in CNS health and disease. Pharmacol Res 86: 32-41.

Mazier W, Saucisse N, Gatta-Cherifi B, Cota D (2015). The endocannabinoid system: pivotal orchestrator of obesity and metabolic disease. Trends Endocrinol Metab 26: 524-537.

Melis T, Succu S, Sanna F, Boi A, Argiolas A, Melis MR (2007). The cannabinoid antagonist SR 141716A (Rimonabant) reduces the increase of extra-cellular dopamine release in the rat nucleus accumbens induced by a novel high palatable food. Neurosci Lett 419: 231-235.

Molvarec A, Fugedi G, Szabo E, Stenczer B, Walentin S, Rigo J Jr (2015). Decreased circulating anandamide levels in preeclampsia. Hypertens Res 38: 413-418.

Monteleone AM, Di Marzo V, Aveta T, Piscitelli F, Dalle Grave R, Scognamiglio P et al (2015). Deranged endocannabinoid responses to hedonic eating in underweight 
and recently weight-restored patients with anorexia nervosa. Am J Clin Nutr 101: 262-269.

Monteleone AM, Di Marzo V, Monteleone P, Dalle Grave R, Aveta T, Ghoch ME et al (2016). Responses of peripheral endocannabinoids and endocannabinoid-related compounds to hedonic eating in obesity. Eur J Nutr 55: 1799-1805.

Monteleone P, Piscitelli F, Scognamiglio P, Monteleone AM, Canestrelli B, Di Marzo $V$ et al (2012). Hedonic eating is associated with increased peripheral levels of ghrelin and the endocannabinoid 2-arachidonoyl-glycerol in healthy humans: a pilot study. J Clin Endocrinol Metab 97: E917-E924.

Movahed P, Evilevitch V, Andersson TL, Jonsson BA, Wollmer P, Zygmunt PM et al (2005). Vascular effects of anandamide and $\mathrm{N}$-acylvanillylamines in the human forearm and skin microcirculation. Br J Pharmacol 146: 171-179.

Nedeltcheva AV, Killkus JM, Imperial J, Kasza K, Schoeller DA, Penev PD (2009). Sleep curtailment is accompanied by increased intake of calories from snacks. Am J Clin Nutr 89: 126-133.

Nomura DK, Hudak CS, Ward AM, Burston JJ, Issa RS, Fisher KJ et al (2008). Monoacylglycerol lipase regulates 2-arachidonoylglycerol action and arachidonic acid levels. Bioorg Med Chem Lett 18: 5875-5878.

Osei-Hyiaman D, Depetrillo M, Pacher P, Liu J, Radaeva S, Batkai S et al (2005). Endocannabinoid activation at hepatic $\mathrm{CB}(1)$ receptors stimulates fatty acid synthesis and contributes to diet-induced obesity. J Clin Invest 115: 1298-1305.

Pagotto U, Marsicano G, Cota D, Lutz B, Pasquali R (2006). The emerging role of the endocannabinoid system in endocrine regulation and energy balance. Endocr Rev 27: 73-100

Pastor A, Fernandez-Aranda F, Fito M, Jimenez-Murcia S, Botella C, Fernandez-Real JM et al (2016). A lower olfactory capacity is related to higher circulating concentrations of endocannabinoid 2-arachidonoylglycerol and higher body mass index in women. PLOS ONE 11: e0148734.

Patel S, Carrier EJ, Ho WS, Rademacher DJ, Cunningham S, Reddy DS et al (2005). The postmortal accumulation of brain $\mathrm{N}$-arachidonylethanolamine (anandamide) is dependent upon fatty acid amide hydrolase activity. J Lipid Res 46: 342-349.

Patel S, Wohlfeil ER, Rademacher DJ, Carrier EJ, Perry LJ, Kundu A et al (2003). The general anesthetic propofol increases brain $\mathrm{N}$-arachidonylethanolamine (anandamide) content and inhibits fatty acid amide hydrolase. $\mathrm{Br} J$ Pharmacol 139: 1005-1013.

Patsenker E, Sachse P, Chicca A, Gachet MS, Schneider V, Mattsson J et al (2015). Elevated levels of endocannabinoids in chronic hepatitis C may modulate cellular immune response and hepatic stellate cell activation. Int J Mol Sci 16: 7057-7076.

Pavon FJ, Araos P, Pastor A, Calado M, Pedraz M, Campos-Cloute R et al (2013). Evaluation of plasma-free endocannabinoids and their congeners in abstinent cocaine addicts seeking outpatient treatment: impact of psychiatric co-morbidity. Addict Biol 18: 955-969.

Pellkofer HL, Havla J, Hauer D, Schelling G, Azad SC, Kuempfel T et al (2013). The major brain endocannabinoid 2-AG controls neuropathic pain and mechanical hyperalgesia in patients with neuromyelitis optica. PLOS ONE 8: e71500.

Pfitzer T, Niederhoffer N, Szabo B (2005). Search for an endogenous cannabinoidmediated effect in the sympathetic nervous system. Naunyn Schmiedebergs Arch Pharmacol 371: 9-17.

Phillips C, Baktir MA, Srivatsan M, Salehi A (2014). Neuroprotective effects of physical activity on the brain: a closer look at trophic factor signaling. Front Cell Neurosci 8: 170

Piomelli D, Hohmann AG, Seybold V, Hammock BD (2014). A lipid gate for the peripheral control of pain. J Neurosci 34: 15184-15191.

Potvin S, Kouassi E, Lipp O, Bouchard RH, Roy MA, Demers MF et al (2008). Endogenous cannabinoids in patients with schizophrenia and substance use disorder during quetiapine therapy. J Psychopharmacol 22: 262-269.

Pryor KO, Root JC, Mehta M, Stern E, Pan H, Veselis RA et al (2015). Effect of propofol on the medial temporal lobe emotional memory system: a functional magnetic resonance imaging study in human subjects. $\mathrm{Br} J$ Anaesth 115(Suppl 1): i104-i113.

Raichlen DA, Foster AD, Gerdeman GL, Seillier A, Giuffrida A (2012). Wired to run: exercise-induced endocannabinoid signaling in humans and cursorial mammals with implications for the 'runner's high'. J Exp Biol 215(Pt 8): 1331-1336.

Raichlen DA, Foster AD, Seillier A, Giuffrida A, Gerdeman GL (2013). Exerciseinduced endocannabinoid signaling is modulated by intensity. Eur J Appl Physiol 113: 869-875.

Ramaekers JG, Kauert G, van Ruitenbeek P, Theunissen EL, Schneider E, Moeller MR (2006). High-potency marijuana impairs executive function and inhibitory motor control. Neuropsychopharmacology 31: 2296-2303.

Ramsden CE, Zamora D, Makriyannis A, Wood JT, Mann JD, Faurot KR et al (2015). Diet-induced changes in n-3- and n-6-derived endocannabinoids and reductions in headache pain and psychological distress. J Pain 16: 707-716.

Romano A, Gallelli CA, Koczwara JB, Braegger FE, Vitalone A, Falchi M et al (2017). Role of the area postrema in the hypophagic effects of oleoylethanolamide. Pharmacol Res 122: 20-34.
Rouzer CA, Ghebreselasie K, Marnett LJ (2002). Chemical stability of 2-arachidonylglycerol under biological conditions. Chem Phys Lipids 119: 69-82.

Ruderman NB, Keller C, Richard AM, Saha AK, Luo Z, Xiang X et al (2006). Interleukin-6 regulation of AMP-activated protein kinase. Potential role in the systemic response to exercise and prevention of the metabolic syndrome. Diabetes 55(Suppl 2): S48-S54.

Saad A, Dalla Man C, Nandy DK, Levine JA, Bharucha AE, Rizza RA et al (2012). Diurnal pattern to insulin secretion and insulin action in healthy individuals. Diabetes 61: 2691-2700.

Schaefer C, Enning F, Mueller JK, Bumb JM, Rohleder C, Odorfer TM et al (2014). Fatty acid ethanolamide levels are altered in borderline personality and complex posttraumatic stress disorders. Eur Arch Psychiatry Clin Neurosci 264: 459-463.

Scheer FA (2016). Hungry for sleep: a role for endocannabinoids? Sleep 39: 495-496.

Schelling G, Hauer D, Azad SC, Schmoelz M, Chouker A, Schmidt M et al (2006). Effects of general anesthesia on anandamide blood levels in humans. Anesthesiology 104: 273-277.

Schmidt A, Brune K, Hinz B (2006). Determination of the endocannabinoid anandamide in human plasma by high-performance liquid chromatography. Biomed Chromatogr 20: 336-342.

Schroeder C, Batkai S, Engeli S, Tank J, Diedrich A, Luft FC et al (2009). Circulating endocannabinoid concentrations during orthostatic stress. Clin Auton Res 19: 343-346.

Seagard JL, Dean C, Patel S, Rademacher DJ, Hopp FA, Schmeling WT et al (2004). Anandamide content and interaction of endocannabinoid/GABA modulatory effects in the NTS on baroreflex-evoked sympathoinhibition. Am J Physiol Heart Circ Physiol 286: H992-H1000.

Seagard JL, Hopp FA, Hillard CJ, Dean C (2005). Effects of endocannabinoids on discharge of baroreceptive NTS neurons. Neurosci Lett 381: 334-339.

Sergi M, Battista N, Montesano C, Curini R, Maccarrone M, Compagnone D (2013). Determination of the two major endocannabinoids in human plasma by mu-SPE followed by HPLC-MS/MS. Anal Bioanal Chem 405: 785-793.

Sido JM, Nagarkatti PS, Nagarkatti M (2016). Production of endocannabinoids by activated T cells and B cells modulates inflammation associated with delayed-type hypersensitivity. Eur J Immunol 46: 1472-1479.

Silvestri C, Di Marzo V (2013). The endocannabinoid system in energy homeostasis and the etiopathology of metabolic disorders. Cell Metab 17: 475-490.

Sipe JC, Scott TM, Murray S, Harismendy O, Simon GM, Cravatt BF et al (2010). Biomarkers of endocannabinoid system activation in severe obesity. PLOS ONE 5: e8792.

Soethoudt M, Grether U, Fingerle J, Grim TW, Fezza F, de Petrocellis L et al (2017). Cannabinoid CB2 receptor ligand profiling reveals biased signalling and off-target activity. Nat Commun 8: 13958.

Solowij N, Michie PT (2007). Cannabis and cognitive dysfunction: parallels with endophenotypes of schizophrenia? J Psychiatry Neurosci 32: 30-52.

Spagnolo PA, Ramchandani VA, Schwandt ML, Kwako LE, George DT, Mayo LM et al (2016). FAAH gene variation moderates stress response and symptom severity in patients with posttraumatic stress disorder and comorbid alcohol dependence. Alcohol Clin Exp Res 40: 2426-2434.

Sparling PB, Giuffrida A, Piomelli D, Rosskopf L, Dietrich A (2003). Exercise activates the endocannabinoid system. Neuroreport 14: 2209-2211.

St-Onge MP, Roberts AL, Chen J, Kelleman M, O'Keeffe M, RoyChoudhury A et al (2011). Short sleep duration increases energy intakes but does not change energy expenditure in normal-weight individuals. Am J Clin Nutr 94: 410-416.

Steptoe A, Hamer M, Chida Y (2007). The effects of acute psychological stress on circulating inflammatory factors in humans: a review and meta-analysis. Brain Behav Immun 21: 901-912.

Sticht MA, Rock EM, Limebeer CL, Parker LA (2015). Endocannabinoid Mechanisms Influencing Nausea. Int Rev Neurobiol 125: 127-162.

Syed SK, Bui HH, Beavers LS, Farb TB, Ficorilli J, Chesterfield AK et al (2012). Regulation of GPR119 receptor activity with endocannabinoid-like lipids. Am J Physiol Endocrinol Metab 303: E1469-E1478.

Szafran B, Borazjani A, Lee JH, Ross MK, Kaplan BL (2015). Lipopolysaccharide suppresses carboxylesterase $2 \mathrm{~g}$ activity and 2-arachidonoylglycerol hydrolysis: A possible mechanism to regulate inflammation. Prostaglandins Other Lipid Mediat 121(Pt B): 199-206.

Szuhany KL, Bugatti M, Otto MW (2015). A meta-analytic review of the effects of exercise on brain-derived neurotrophic factor. J Psychiatr Res 60: 56-64.

Thieme U, Schelling G, Hauer D, Greif R, Dame T, Laubender RP et al (2014). Quantification of anandamide and 2-arachidonoylglycerol plasma levels to examine potential influences of tetrahydrocannabinol application on the endocannabinoid system in humans. Drug Test Anal 6: 17-23.

Ueda N, Yamanaka K, Yamamoto S (2001). Purification and characterization of an acid amidase selective for $\mathrm{N}$-palmitoylethanolamine, a putative endogenous antiinflammatory substance. J Biol Chem 19: 19. 
Urhausen A, Gabriel H, Kindermann W (1995). Blood hormones as markers of training stress and overtraining. Sports Med 20: 251-276.

Urquhart P, Nicolaou A, Woodward DF (2015). Endocannabinoids and their oxygenation by cyclo-oxygenases, lipoxygenases and other oxygenases. Biochim Biophys Acta 1851: 366-376.

Van Cauter E, Polonsky KS, Scheen AJ (1997). Roles of circadian rhythmicity and sleep in human glucose regulation. Endocr Rev 18: 716-738.

Van Gaal LF, Rissanen AM, Scheen AJ, Ziegler O, Rossner S (2005). Effects of the cannabinoid-1 receptor blocker rimonabant on weight reduction and cardiovascular risk factors in overweight patients: 1-year experience from the RIO-Europe study. Lancet 365: 1389-1397.

van Hell HH, Jager G, Bossong MG, Brouwer A, Jansma JM, Zuurman L et al (2012). Involvement of the endocannabinoid system in reward processing in the human brain. Psychopharmacology 219: 981-990.

Varga K, Wagner JA, Bridgen DT, Kunos G (1998). Platelet- and macrophagederived endogenous cannabinoids are involved in endotoxin-induced hypotension. FASEB J 12: 1035-1044.

Vaughn LK, Denning G, Stuhr KL, de Wit H, Hill MN, Hillard CJ (2010). Endocannabinoid signalling: has it got rhythm? Br J Pharmacol 160: 530-543.

Venkatesan T, Zadvornova Y, Raff H, Hillard CJ (2016). Endocannabinoid-related lipids are increased during an episode of cyclic vomiting syndrome. Neurogastroenterol Motil 28: 1409-1418.

Verty AN, Allen AM, Oldfield BJ (2009). The effects of rimonabant on brown adipose tissue in rat: implications for energy expenditure. Obesity (Silver Spring) 17: 254-261.

Vettor R, Pagano C (2009). The role of the endocannabinoid system in lipogenesis and fatty acid metabolism. Best Pract Res Clin Endocrinol Metab 23: 51-63.

Viader A, Blankman JL, Zhong P, Liu X, Schlosburg JE, Joslyn CM et al (2015). Metabolic Interplay between Astrocytes and Neurons Regulates Endocannabinoid Action. Cell Rep 12: 798-808.
Vogeser M, Hauer D, Christina Azad S, Huber E, Storr M, Schelling G (2006). Release of anandamide from blood cells. Clin Chem Lab Med 44: 488-491.

Wang Y, Liu Y, Ito Y, Hashiguchi T, Kitajima I, Yamakuchi M et al (2001). Simultaneous measurement of anandamide and 2-arachidonoylglycerol by polymyxin b-selective adsorption and subsequent high-performance liquid chromatography analysis: increase in endogenous cannabinoids in the sera of patients with endotoxic shock. Anal Biochem 294: 73-82.

Wei D, Lee D, Li D, Daglian J, Jung KM, Piomelli D (2016). A role for the endocannabinoid 2-arachidonoyl-sn-glycerol for social and high-fat food reward in male mice. Psychopharmacology (Berl) 233: 1911-1919.

Weis F, Beiras-Fernandez A, Hauer D, Hornuss C, Sodian R, Kreth S et al (2010a). Effect of anaesthesia and cardiopulmonary bypass on blood endocannabinoid concentrations during cardiac surgery. Br J Anaesth 105: 139-144.

Weis F, Beiras-Fernandez A, Sodian R, Kaczmarek I, Reichart B, Beiras A et al (2010b). Substantially altered expression pattern of cannabinoid receptor 2 and activated endocannabinoid system in patients with severe heart failure. $\mathrm{J} \mathrm{Mol} \mathrm{Cell}$ Cardiol 48: 1187-1193.

Wilker S, Pfeiffer A, Elbert T, Ovuga E, Karabatsiakis A, Krumbholz A et al (2016). Endocannabinoid concentrations in hair are associated with PTSD symptom severity. Psychoneuroendocrinology 67: 198-206.

Yamakawa K, Matsunaga M, Isowa T, Kimura K, Kasugai K, Yoneda M et al (2009). Transient responses of inflammatory cytokines in acute stress. Biol Psychol 82: 25-32.

Yi B, Nichiporuk I, Nicolas M, Schneider S, Feuerecker M, Vassilieva G et al (2016). Reductions in circulating endocannabinoid 2-arachidonoylglycerol levels in healthy human subjects exposed to chronic stressors. Prog Neuropsychopharmacol Biol Psychiatry 67: 92-97.

Zygmunt PM, Petersson J, Andersson DA, Chuang H, Sorgard M, Di Marzo V et al (1999). Vanilloid receptors on sensory nerves mediate the vasodilator action of anandamide. Nature 400: 452-457. 